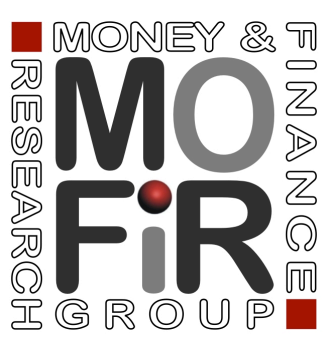

TARIFFS, DOMESTIC IMPORT SUBSTITUTION AND TRADE DIVERSION IN INPUT-OUTPUT PRODUCTION NETWORKS: HOW TO DEAL WITH BREXIT

Raffaele Giammetti

Working paper no. 152

March 2019 


\title{
Tariffs, Domestic Import Substitution and Trade Diversion in Input-Output Production Networks: how to deal with Brexit
}

\author{
Raffaele Giammetti ${ }^{a}$
}

\begin{abstract}
This paper challenges and complements existing studies on the economic impact of Brexit providing a discussion of the UK's decision to leave the EU and how it will affect international trade networks and value-added. Using the World Input-Output Database, we develop a multi-sector inter-country model that allows us to identify the channels through which the economic effects of Brexit would propagate. The inclusion of global value chains and indirect Brexit effects in the model leads to estimates that diverge with the results of the main literature. Indeed our findings, suggest that Brexit could be risky and costly not only for the UK but also for many EU countries. Furthermore, building on the Dietzenbacher and Lahr (2013) method of hypothetical expansion, we develop a second model and present the first empirical analysis on the consequences of domestic import substitution and trade diversion policies in Input-Output schemes. We found that allowing sectors and countries to partly substitute foreign products, leads to significantly lower losses for both macro-regions. In the second model, the UK and EU27 would lose, at worst, the 0.05 and 0.5 percent of value-added, respectively.
\end{abstract}

Keywords: Brexit, trade barriers, tariffs, input-output analysis, value chains, import substitution, production networks.

JEL Classification: C67, R15, F13, F14, O21

\section{Introduction}

The United Kingdom (UK) decision to leave the European Union (EU) took many by surprise. Since then, the debate around Brexit, focused on the reasons and consequences of this decision. Several scholars and political commentators attempted to explain the support for the Leave option in the referendum, emphasizing the role played by political issues such as those of immigration and sovereignty, and the growing trade deficit the UK runs with many European countries. In particular, the adverse trade relationships with Europe helped to spread a feeling of intolerance towards Europe (Los et al., 2017) and to develop a rejection of globalisation (Colantone and Stanig, 2018; Rodrik, 2018a), which resulted in the

\footnotetext{
${ }^{\text {a }}$ Università Politecnica delle Marche - Department of Economics and Social Sciences, Piazzale Martelli 8 - 60121 Ancona, Italy.

Part of this research has been performed while I was visiting the Department of Economics at the University of Essex, therefore, I would like to thank Sheri Marina Markose who provided insight and expertise that greatly assisted the research. I also thank Katie Chapman and Inacio Manjama for assistance and comments that improved the manuscript. I would also like to show my gratitude to the organizers and participants of the University of Trento's XIX Trento Summer School in Adaptive Economic Dynamics, for useful comments and suggestions, as well as participants at the 2018 ESCoS conference in Naples, and the 2018 DySES conference in Paris. Finally, I am immensely grateful to Erik Dietzenbacher, Nadia Garbellini, Bart Los and Ariel Wirkierman for their insightful comments and suggestions at the very early stage of this research, although any errors are my own and should not tarnish the reputations of these esteemed persons.
}

Email: r.giammetti@pm.univpm.it 
victory for the Leave campaign. It is therefore not surprising that most of the studies regarding the likely economic implication of such an extraordinary event focus on the impact Brexit will have on international trade.

The trade effects of Brexit are particularly complex, as in the age of globalisation, production processes and global value chains (GVCs) are increasingly fragmented and often involve intermediate inputs crossing borders several times until they are sold as a final product. However, the predictions on the implications of Brexit often fall short in understanding the effect of any trade shocks within these highly complex and interconnected systems. Rather, the main analyses conducted so far are wholly UK centric and hence conclude that Brexit will result in heavy losses especially for the UK. The present paper challenges and complements these studies in two directions.

First, using the recently constructed World Input-Output Database (WIOD), a comprehensive and granular model is developed that offers detailed information on the distributional effects of Brexit as a trade shock and the impact it will have on the value-added of the UK, EU, and extra-EU countries. The model includes direct and indirect trade via GVCs and provides estimates of the direct and indirect impact of Brexit at the industry level. Include indirect effects means consider the implications Brexit will have on third-party countries. For example, let us consider an Italian car that to be assembled requires components such as steel, glass, plastic, rubber, etc., which are provided by different sectors in different countries. Thus, if the UK demand for Italian cars will reduce due to Brexit, this means that production losses would propagate indirectly in all sectors and countries providing inputs embedded in Italian cars. The inclusion of GVCs and indirect Brexit effects in our model leads to estimates that diverge with the results of the main literature. Indeed our findings, comparable with other studies that include indirect Brexit effects such as Vandenbussche et al. (2017) and W. Chen et al. (2018), suggest that Brexit could be risky and costly not only for the UK but also for EU countries, especially Ireland, Germany, Belgium, and the Netherlands, with Ireland facing losses similar or even greater than those of the UK. Furthermore, the predictions show that the total value-added losses for the EU27, ranging from \$54 billion under a free trade agreement scenario to $\$ 218$ billion under a no-deal scenario, are greater than in the UK. However, in line with the results that circulate in the literature, our model simulation shows that the UK, as single country, is still the most affected by Brexit, facing value-added losses of $\$ 36$ billion and $\$ 135$ billion for the soft and hard Brexit scenarios, respectively.

The second novelty of the paper is to challenge the theoretical framework of traditional trade models. In particular, we move away from the traditional assumption underlying standard trade models, according to which trade liberalisation always increases welfare and we address the question, are there any economic policies that would mitigate or even reverse the negative Brexit effects? Rodrick (2018a, 2018b, 2018c) states that under circumstances of weak domestic growth and growing trade deficit, trade protectionism would be preferable to unconditional free trade. Building on this remark, we develop a second model that considers Brexit as a special case in which a country implements a protectionist trade policy in order to rebalance the external accounts and boost domestic growth. Hence, we introduce the hypotheses that in response to Brexit, UK trade will be partly diverted to extra-EU countries and EU imported products will be partly substituted by domestic purchases. Conversely, on the other side of the Channel, we assume that EU countries will partly substitute UK imported products by intra-EU purchases. The inclusion of domestic import substitution and trade diversion policies in the model leads to different estimates about the potential impact of Brexit on both macro-regions. In particular, we find the absolute and relative losses in value-added production for the UK and for each EU27 member state to be significantly lower compared to the results shown in the Brexit literature and in our first model. Notably, estimated losses in the UK ranging from $\$ 1.4$ billion in the soft Brexit scenario to a surprisingly gain of $\$ 10.6$ billion in the hard Brexit scenario. Outside the UK, losses are larger, although significantly below to the first model estimates. A potential explanation for these lower estimates is that in our second model trade barriers 
would not necessarily mean negative economic shocks, because we allow sectors and countries to partly substitute foreign products which are rendered less competitive due to tariffs.

The models developed are highly influenced by Koopman et al. (2014), Los et al. (2016), Dietzenbacher and Lahr (2013) and W. Chen et al. (2018), whose insightful work on IO data analysis provides the fundamentals for our analysis. Dietzenbacher and Lahr (2013), in particular, inspire the hypothetical partial extraction and partial expansion methods that are used in the models. The methodology follows most closely that of Vandenbussche et al. (2017) who, like in this paper, allow for tariff and elasticity heterogeneity across countries and sectors. This is particularly important as potential post-Brexit tariffs vary greatly across sectors and differences in elasticities can heavily influence the outcome of a trade shock.

The work is organised as follows. The second section explores and discusses the relevant literature. The third and fourth section examines the historical trend of UK bilateral trade relationships, and the main features of the current trade relationships, respectively. The fifth section describes the model and methodology used for analysis. The sixth and seventh section present and discuss the results and lastly, the paper offers some concluding remarks.

\section{The Economic Impact of Brext: Literature Review}

The UK's decision to leave the EU has led to an extensive body of work by academics and governing institutions that attempt to quantify the economic and trade impacts of Brexit on the UK, the EU and the rest of the world. This section reviews some of that literature and discusses how it has influenced the work in this paper.

\subsection{Gravity Models in Brexit Impact Studies}

The models employed in much of the relevant literature can be broadly lumped into four main groups: gravity models, computable general equilibrium models (CGE), new quantitative trade models (NQTM) and econometric models. A gravity model is a well-known and well-established econometric approach for estimating the economic impact of trade agreements on trade flows between countries (Piermartini and Teh, 2005; Plummer et al., 2010; Head and Mayer, 2014). It is an ex post method that relies on existing data to evaluate the effects of changes in variables that in some way affect barriers to trade between countries. Gravity models for trade are analogous to Newton's physical law of gravity in which the attraction of planetary bodies is directly proportional to their size and inversely proportional to their distance apart (Gudgin et al., 2017a). Gravity models likewise assume that bilateral trade flows are increasing in relation to the size of the trade partner's economy and decreasing in relation to its geographic distance. The results of the econometric analysis indicate how far the estimated model can be used to explain past trade flows and how important free trade agreements are in this context.

For all these reasons, gravity models sound suitable to study the consequences of Brexit. In fact, in their assessments, published shortly before the referendum, both the UK Treasury (2016) and OECD (Kierzenkowski et al., 2016) employ gravity models to quantify post-Brexit trade between UK and EU. The UK Treasury report calculates the benefit of UK's membership in terms of extra trade with the EU and assumes that most of this trade would be lost to the UK on leaving the EU and adopting WTO rules. Likewise, the study computes the change in foreign direct investment (FDI) and the impact on productivity resulting from the changes in trade and FDI. Then, the results are entered into the NiGEM, a multi-national general equilibrium-forecasting model, to calculate the likely impact on GDP and unemployment. The OECD's approach parallels the Treasury in computing the change in trade, FDI and their impact on productivity, in addition, the OECD study considers the potential changes in regulation, 
migration, investment in R\&D and reduced managerial quality. Again, the results of these changes are entered into the NiGEM macro-economic model to predict overall impacts on GDP, incomes, and unemployment. The mid-range estimates of the reduction in GDP in 2030 under a WTO scenario are 6.2 percent for the Treasury and 5.1 percent for the OECD. However, as pointed out by Gudgin et al. (2017a, b) these pessimistic predictions depend essentially on the assumptions of the underlying gravity models adopted. Changing the method of obtaining the gravity equation, the authors suggest that the impact on UK's GDP is substantially smaller ranging from 1 percent in the milder Brexit scenario to 4 percent in the more severe scenario (Gudgin, 2017a). Therefore, their conclusion is that the gravity model approach lacks the degree of precision needed to make a definitive estimate of the impact of EU membership on trade. Furthermore, although gravity models have a firm theoretical foundation, they do not include the interaction between sectors and markets and are able to explain only trade flows and not welfare or employment. Also for these reasons, some scholars have preferred CGE and NQTM models.

\subsection{CGE and NQTMs in Brexit Impact Studies}

CGE models are standard tools to estimate the impact of trade policy measures such as trade agreements (Piermartini and Teh, 2005; Plummer et al., 2010). Thus, they are also suited to simulate a Brexit or to quantify the benefits for the UK from free trade of goods and services with other EU member states. As in Walrasian theory, CGE models aim to mimic a simplified version of the whole economy (general equilibrium) - and not only of a single sector or market (partial equilibrium). Therefore, they usually take into account many countries and sectors as well as the main relevant existing channels of economic transactions. Booth et al. (2015) in their report for the think tank Open Europe apply a CGE trade model and present a very detailed study on the impact of Brexit. The authors differentiate between four scenarios resulting in a range of possible effects by 2030: in the worst case, World Trade Organization (WTO) rules between UK and European countries, the UK will bear a loss of 2.2 percent of GDP; in the best case, free trade agreement (FTA) with EU and an extremely ambitious deregulation approach, the UK will gain 1.6 percent of GDP. In the middle, the more political realistic range forecast a 0.8 percent loss of GDP in a pessimistic scenario and a gain of 0.6 percent of GDP in an optimistic scenario.

Rojas-Romagosa (2016) employs a CGE model focusing on trade relationship between the UK and EU countries, especially the Netherlands. In the worst scenario (WTO rules) total trade decrease dramatically for the UK leading to a fall in GDP of about 4 percent. This loss becomes more modest in the FTA scenario. However, in CGE modelling, results heavily depend on the assumptions made, the structure of the model, and data used. The complexity of CGE models makes it difficult to understand the extent to which the results depend on these features. Finally, beside the high complexity characterizing this model, CGE are 'comparative static' models, meaning that results derive from a comparison of the economy equilibrium today with the one achieved when the economic shock is absorbed. The way towards this new equilibrium is not modelled and it is not exactly clear how long the adaptation phase takes (Busch and Matthes, 2016).

Starting from the insight that usual CGE models and several other trade models have a common core under certain assumptions, recently, a new class of trade models has become popular in estimating the effects of FTAs: the NQTMs. These models are based on both gravity equations and basic assumptions of CGE models. The advantage of NQTM over CGE models is a much simpler construction of the model itself, requiring fewer and more straightforward equations than CGE models. This allows for a better understanding of the effect of each parameter taken into consideration. The main idea behind these models is that trade liberalisation tend to increase welfare because it allows countries specialisation in their comparative advantages areas leading to a reduction of costs of goods, services and intermediate input. Thus, considering this underlying claim it is quite simple to imagine the assessment that these models propose of Brexit. 
Three of the most comprehensive and sophisticated Brexit studies (Ottaviano et al., 2014; Aichele and Felbermayr, 2015; Dhingra et al., 2017) use this new method. In particular, influenced by the work of Costinot and Rodríguez-Clare (2014), Ottaviano et al. (2014) quantify the impact of Brexit on multiple sectors of the UK distinguishing between two different scenarios one optimistic and another pessimistic. In the pessimistic case, they assume that the UK will apply the most favourite nations (MFN) tariffs. In the optimistic scenario, authors imagine that the UK will be able to negotiate a better tariff deal in the medium term such as Norway or Switzerland. Hence, they consider that tariffs on goods continue to be zero between the two parts. In both scenarios, UK will face non-tariff barriers (see section 4) in trading with EU, notably, they amount to one-quarter of the reducible non-tariff barriers faced by US exporters to the EU, in the optimistic scenario, and to two-thirds of the reducible non-tariff barriers of US exports to the EU in the pessimistic scenario. The estimates suggest that, in the optimistic case, the level of the UK's GDP will be reduced by 1.1 percent, in the pessimistic case by 3.1 percent in the longer term. In an updated version of the study with broadly similar assumptions, Dhingra et al. (2017) come to comparable results: 1.3 percent loss in the optimistic case, 2.7 percent loss in the pessimistic case. Minor changes apply to the assumptions concerning fiscal benefits which are reduced compared to Ottaviano et al. (2014), particularly in the optimistic (Norwegian) case, and to the non-tariff barriers in the pessimistic case which are higher compared to Ottaviano et al. (2014). Further, Dhingra et al. (2017) also calculate the economic impact of Brexit on other countries. In both scenarios the UK experiences the largest welfare losses, but some countries other than the UK, such as Ireland, Netherlands, Belgium, Denmark, Sweden, and Germany have relatively great welfare losses. In aggregate, the EU27 will experience a GDP loss ranging between 0.1 to 0.4 percent. However, although NQTMs should be regarded as a step forward in estimating the impact of free trade agreements or other trade policy measures ex-ante, still the quantitative results rest on important assumptions (Coutts et al., 2018; W. Chen et al., 2018). As listed by Ottaviano (2014) these micro-foundations are: Dixit-Stiglitz consumer preferences; one factor of production; linear cost function; perfect or monopolistic competition. Whilst macro restrictions are: trade is balanced; aggregate profits are a constant share of aggregate revenues; and the import demand system exhibits constant elasticity of substitution. Therefore, results should be interpreted with caution and taken as qualitative indications (Busch and Matthes, 2016).

\subsection{Econometric Models in Brexit Impact Studies}

Standard econometric studies have also been conducted to assess the economic consequence of Brexit. The economic consultants Cambridge Econometrics (2018), for example, using actual historic data generates estimates for five different scenarios. The report predicts, in the worst case, a global value added 3 percent lower for the UK in 2030. However, the results have to be combined with the decreasing population. The conclusion is that even if global value added in UK will be lower, no substantial reduction in living standards will occur, as measured by per capita global value added. Coutts et al. (2018) and Gudgin et al. (2017a) obtain similar results predicting, in the milder Brexit scenarios, a minor loss of GDP but no loss of per capita GDP and in the worst case a loss of GDP nearer 4 percent.

In a recent IMF Country Report, J. Chen et al. (2018) apply an econometric model to assess the economic impact of Brexit on the other side of the Channel, i.e. on EU27. The IMF researchers develop a multidimensional index that captures the integration between the UK and the EU and use this index to estimate the impact of several Brexit scenarios on EU27 countries. Their findings suggest that the level of output of EU27 countries falls by between 0.06 and up to 1.5 percent, according to the respective scenarios. The data-driven approach typical of econometric studies has the advantage to limit the assumptions which dominate general equilibrium models used in most other Brexit studies. However, the general drawback of econometrics models is that they do not consider global intersectoral production linkages. This limit would represent a relevant weakness. Indeed, according to Johnson (2014) and 
Acemoglu et al. (2012) the emergence of global production networks implies that one can no longer consider bilateral trade in isolation when evaluating trade policy or idiosyncratic shocks. This is particularly true in the case of Brexit considering that most trade between the UK and EU countries is in intermediate inputs (see section 4; Mulabdic et al., 2017; J. Chen et al., 2018). Therefore, neglecting the indirect links via these value chains bring about a partial understanding of the issue and a likely underestimation of the costs of Brexit, especially for EU27 countries. These last observations represent the underlying starting point of the present study.

\subsection{Global Value Chains and Brexit}

To the best of our knowledge, to date, only three studies incorporate supply chain links between countries in their Brexit impact estimation models. Vandenbussche et al. (2017) develop an Input-Output (IO) model of trade that comprises domestic and global value chain linkages between goods and service sectors. Including IO linkages allows considering indirect trade flows, for example domestic production of intermediates can serve as inputs in foreign products and then be exported indirectly to a final destination. Considering the scenarios adopted by Dhingra et al. (2017), Vandenbussche et al. (2017) find that Brexit hits the UK harder than the EU27, in relative terms. However, they find EU27 losses to be substantially higher than other studies pointed out. Another study by W. Chen et al. (2018) examined the exposure of EU regions to Brexit incorporating all effects due to geographically fragmented production processes within the UK, the EU and beyond. Using global IO tables, they link trade to value added and find that UK is far more exposed to Brexit risks than the rest of the EU. At the same time, regions in Ireland, Malta, Netherlands, Belgium and Germany are also likely to be heavily affected by Brexit. Finally, Cappariello et al. (2018) explore the features of global value chain-trade between the EU and the UK, disentangling the complex network of bilateral EU-UK value-added flows. Unlike the two aforementioned studies, Cappariello et al. (2018) do not attempt to quantify the effect of tariffs on growth or macroeconomic, rather the authors compute measures of cost and resistance of trade flows and provide clear evidence of the direct and indirect effects of tariff costs due to Brexit. Their results suggest that tariffs would add almost 1 percentage point to the cost of manufacturing inputs in the UK, while the corresponding input cost in the EU would be only marginally affected.

As stressed in section 4 and 5, the present study builds on the contributions of Vandenbussche et al. (2017) and W. Chen et al. (2018) and provides a method to incorporate trade frictions within an IO framework. Furthermore, we challenge the usual claim underlying the studies reviewed above according to which trade liberalisation always tend to increase welfare and we propose a method to quantify the impact of trade diversion and domestic import substitution policies.

\section{The UK Bilateral Trade Relations}

To illustrate the UK-World trade relations we employ the World Input-Output Database (WIOD). Using this dataset has several advantages: it covers trade in goods and services at the bilateral level allowing for a sectoral investigation, a decomposition of gross exports in value added terms, and a granular analysis of global value chains (see Dietzenbacher et al., 2013 for more details).

At the time of writing the data set covers 43 countries and a model for the rest of the world for the period 2000-2014 and data for 56 sectors classified according to the International Standard Industrial Classification revision 4 (ISIC Rev. 4).

The UK plays an important role in trade relations with the rest of the world. In 2014, the UK records for $3.2 \%$ of world exports and $3.4 \%$ of world imports. As the Figure 1 shows, the EU is the most important UK's trading partner accounting for $39 \%$ of UK exports and $53 \%$ of UK imports. 
However, although the EU is by far the most important source of imports for UK, its significance as destination region has steadily declined over time. This trend has ended up tightening the UK trade deficit with the EU. To gain a deeper understanding of this issue, the UK's net exports (computed on total trade in goods and services) are shown in Figure 2.

On closer inspection, the UK's total trade balance, as Figure 2 highlights, has been in deficit since 2001, due to deficits in trade with EU countries and China that are partly offset by surpluses in trade with the rest of the World, in particular the US.

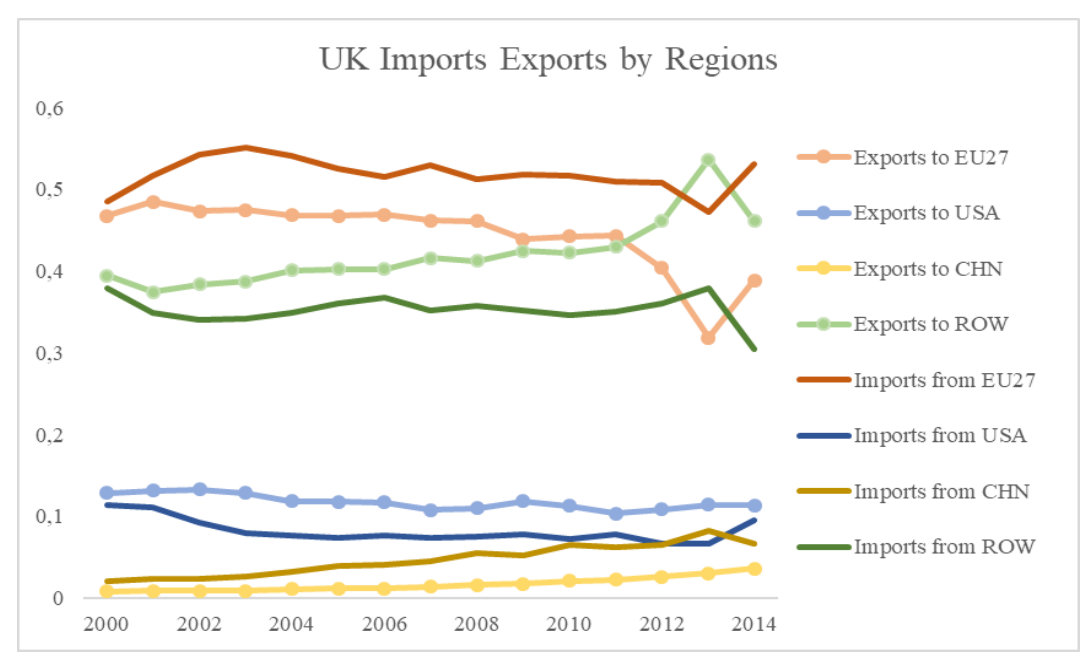

Figure 1. UK imports and exports (as a percentage of total imports/exports) from 2000 to 2014. Decreasing exports from the EU-27 have coincided with increasing exports to ROW and China.

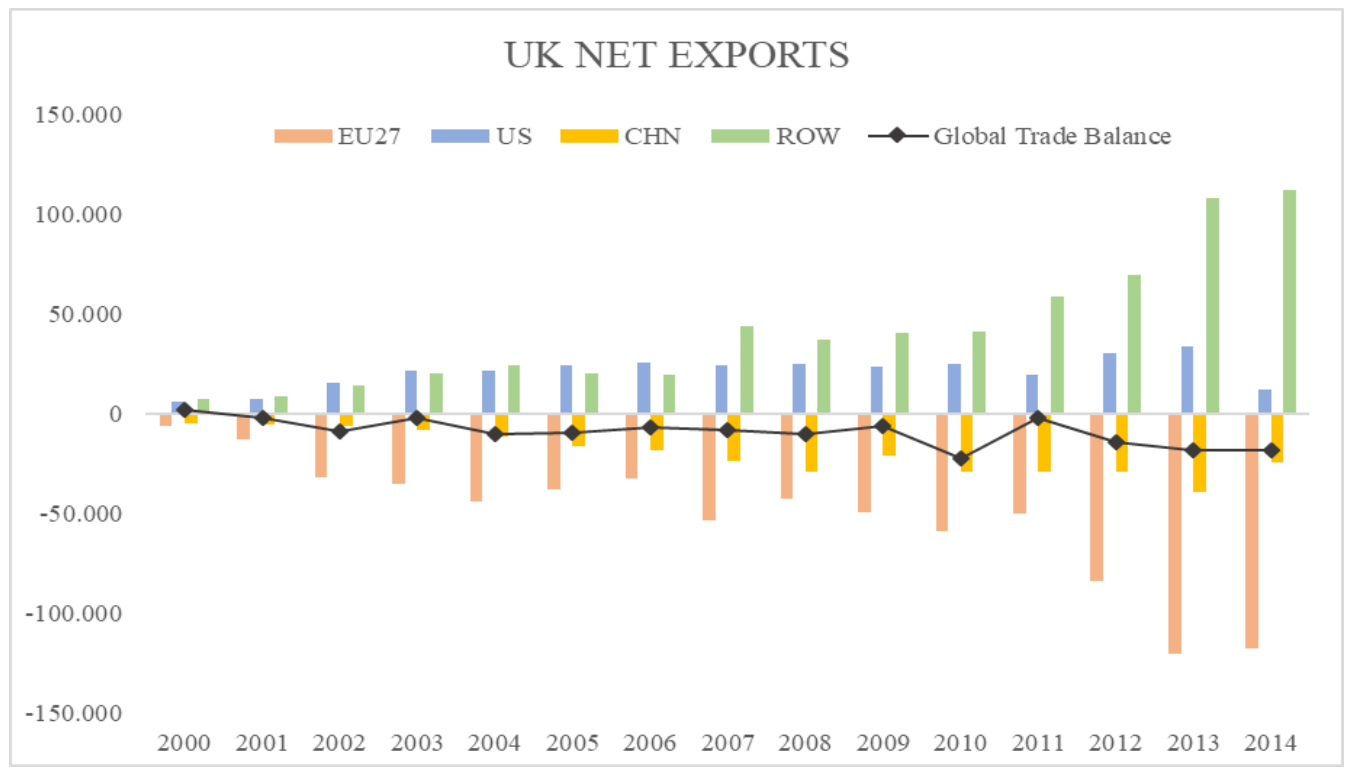

Figure 2. UK net exports and global trade balances from 2000-2014 (millions of \$), including trade balances with EU-27, US, China and ROW. Gradually increasing UK trade deficits with the EU have been mostly offset by trade surpluses with US and ROW.

Utilising the disaggregation of goods and service sectors as in Mulabdic et al. (2017), Figure 3 shows trade balances broken down into goods and services. During the period considered the UK has accumulated an ever-increasing goods trade deficit with the EU, which has been financed by the increase 
in exports of services in the rest of the world. This is consistent with what Mulabdic et al. (2017) call 'servification' of UK trade: the level of total UK trade in goods as a proportion of total trade in goods and services has been gradually declining since 2000 , replaced by the rising share of UK trade in services (Figure 4).

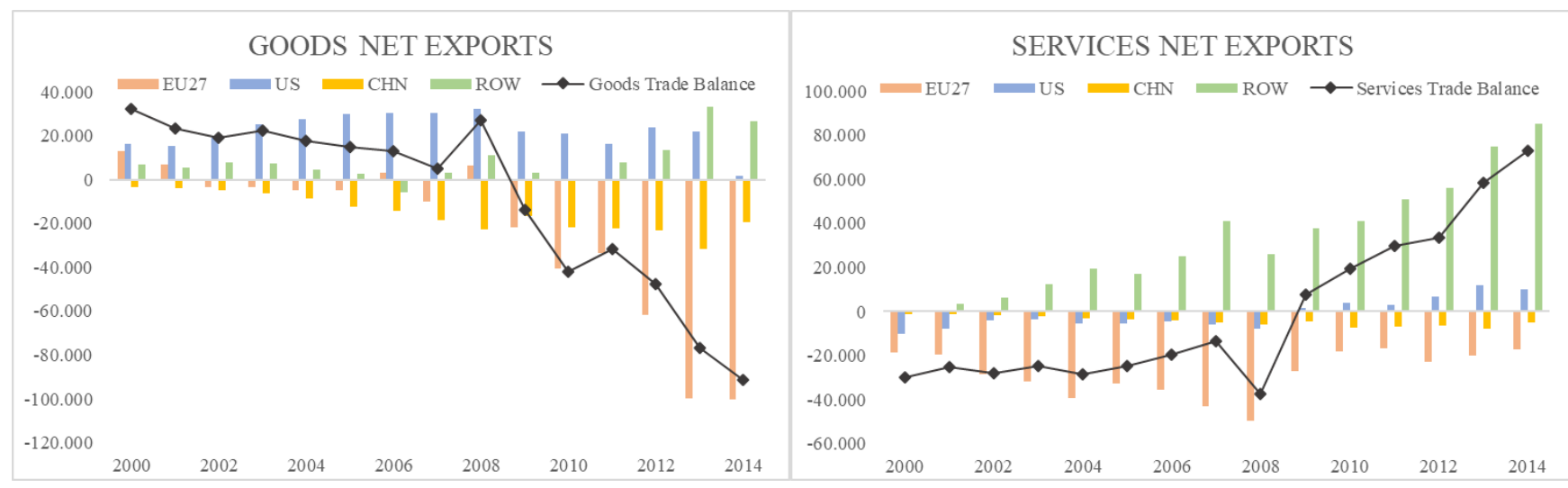

Figure 3. UK goods and services trade balances from 2000-2014 (millions of \$). Increasing trade deficits in goods from EU27 and China has been offset by an increasing trade surplus in services with the US and ROW.

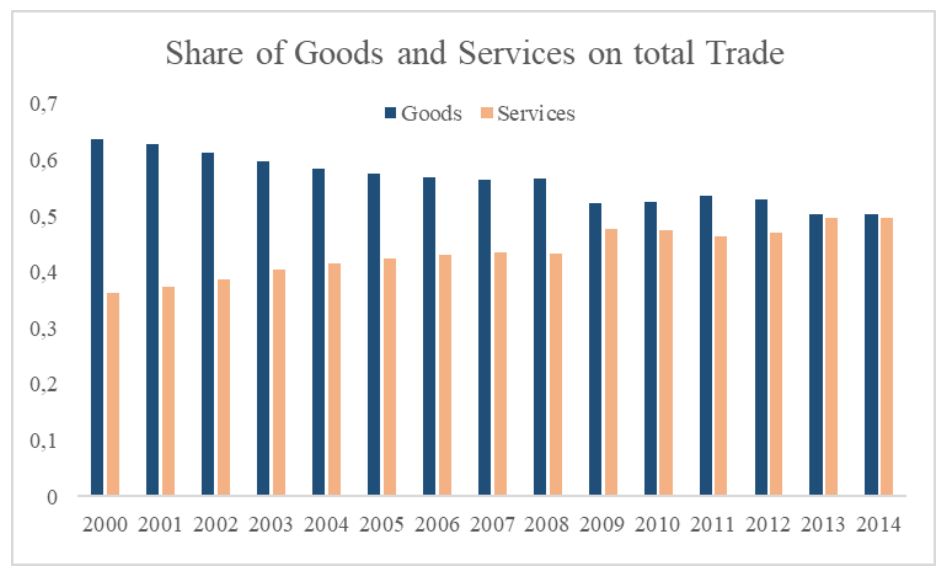

Figure 4. UK trade in goods and services from 2000-2014. The 'servification' of UK trade.

This also supports the work of Rowthorn and Coutts (2004) which reveals that the UK needs large net earnings from the export of services in order to afford a growing manufacturing trade deficit. As suggested by the authors and on closer inspection, those goods sectors from which the UK imports heavily are mostly manufacturing sectors. Figure 5 shows that a whole range of service activities has filled the gap left by the decline of traditional industries. In particular, the UK trade deficit is largely comprised of manufacturing sectors whilst the UK's trade surplus includes mostly knowledge-based service sectors such as Financial and Administrative Services.

The evolution over time of the sectoral balances would suggest a financialisation of UK exports and a 'manufactorisation' of UK imports. As stressed by Coutts and Rowthorn (2013) the substantial shifts that have occurred in the composition of UK trade represent a unique experience. Indeed, the deterioration in the UK manufacturing trade balance has been much greater than in any other advanced economy as well as no other major advanced economy has enjoyed a so huge trade surplus in services. These remarks bring to the fore the debate about the decisive role of manufacturing in the paths of development and growth (Kaldor, 1966, 1975) and about the process of de-industrialisation of the UK denounced by Joseph 
Chamberlain at the end of the XIX century in his contributions on tariff reforms (Kamitake, 1990). The process of de-industrialisation features the economies, in which the share of manufacturing is declining, in terms of contribution to GDP, employment and export earnings, with respect to other sectors (Rowthorn and Coutts, 2004). A long debate on the reasons for the deterioration in the UK manufacturing trade balance ended with the awareness that a substantial reorientation away from manufacturing towards other activities was inevitable due to technological structural changes (Singh, 1977; Rowthorn and Wells, 1987; Rowthorn and Coutts, 2004). However, Rowthorn and Coutts (2004) warn that it is wrong to relegate manufacturing to the past thinking that it is no longer important in a modern economy. According to a more recent contribution by the same authors, this is true especially for the UK economy. Coutts and Rowthorn (2013), indeed, highlight the importance of manufacturing industry for the UK balance of payments, calling for a safeguard and an improvement of the trade performance of this sector.

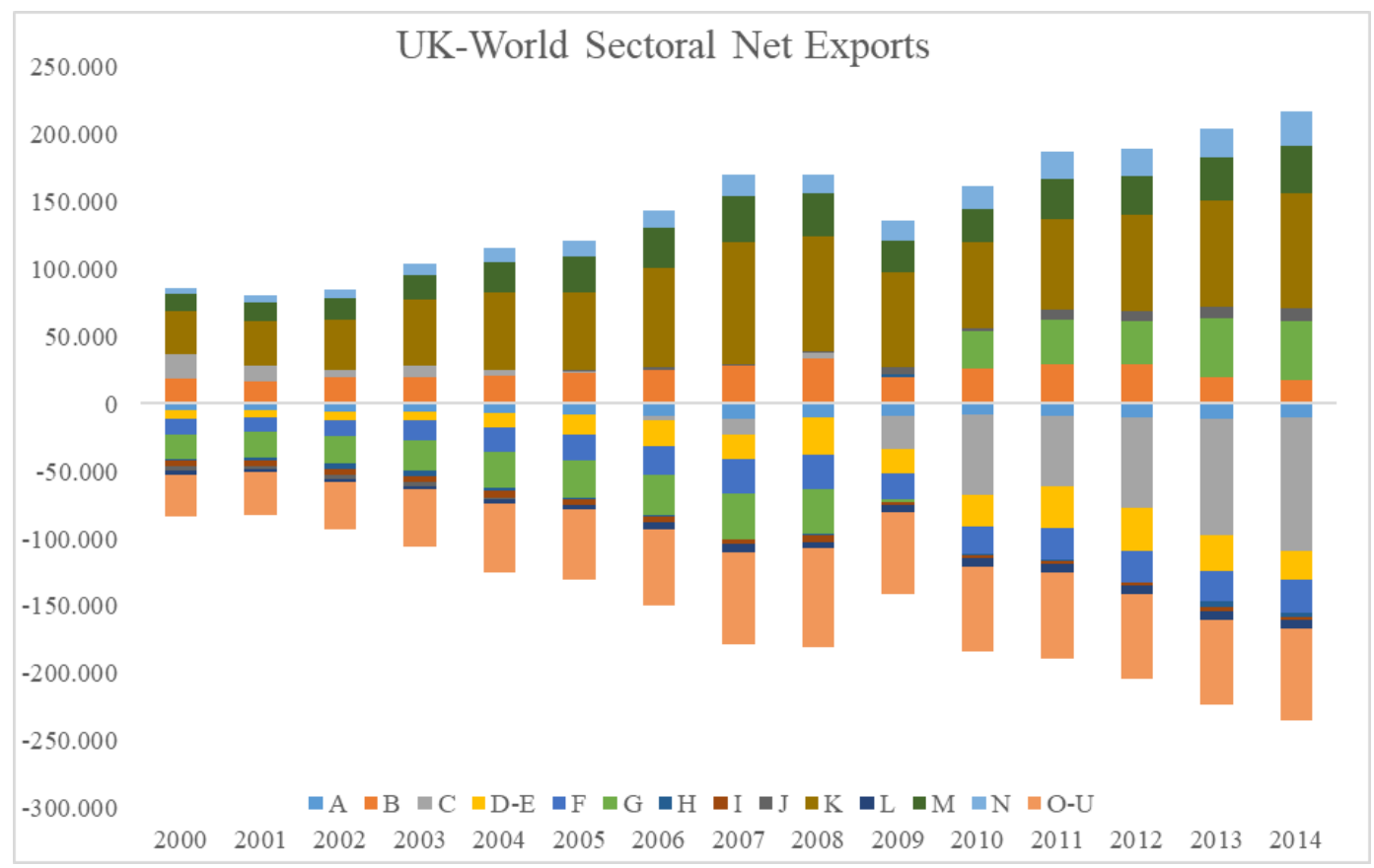

Figure 5. UK sectoral trade balances between 2000 and 2014 (millions of \$). Increasing trade deficits in manufactured goods (C), have been offset by trade surpluses in knowledge-based service sectors $(K, N, M)$. Legend codes: A-Agriculture and Fishing, B-Mining, C-Manufacturing, D-E-Electricity, Gas and Water Supply, F-Construction, G-Wholesale Trade, HTransportation, I-Accommodation and Food Services, J-ICT Services, K-Finance and Insurance Services, L-Real Estate activities, $M$-Scientific Activities, $N$ - Administrative Services, $O-U$-Public and Other Services.

Looking at the sectoral trade balances by regions, Figure 6 shows that the United Kingdom has accumulated a year-on-year deficit against the European manufacturing sector, which is partially compensated by a surplus in the financial sector towards non-European countries. According to Los et al. (2017) findings, these evidence suggest one of the main reasons for which UK voted to leave EU. Indeed regions that are more economically interdependent with EU markets and driven by manufacturing sectors, tended to vote leave (Becker et al., 2017 and Springford et al., 2016 ); regions that are the least dependent on EU markets and were perceived to have most benefited from globalisation displayed the strongest proremain votes (Springford et al., 2016). As known, the referendum established that the former prevailed on the latter. 


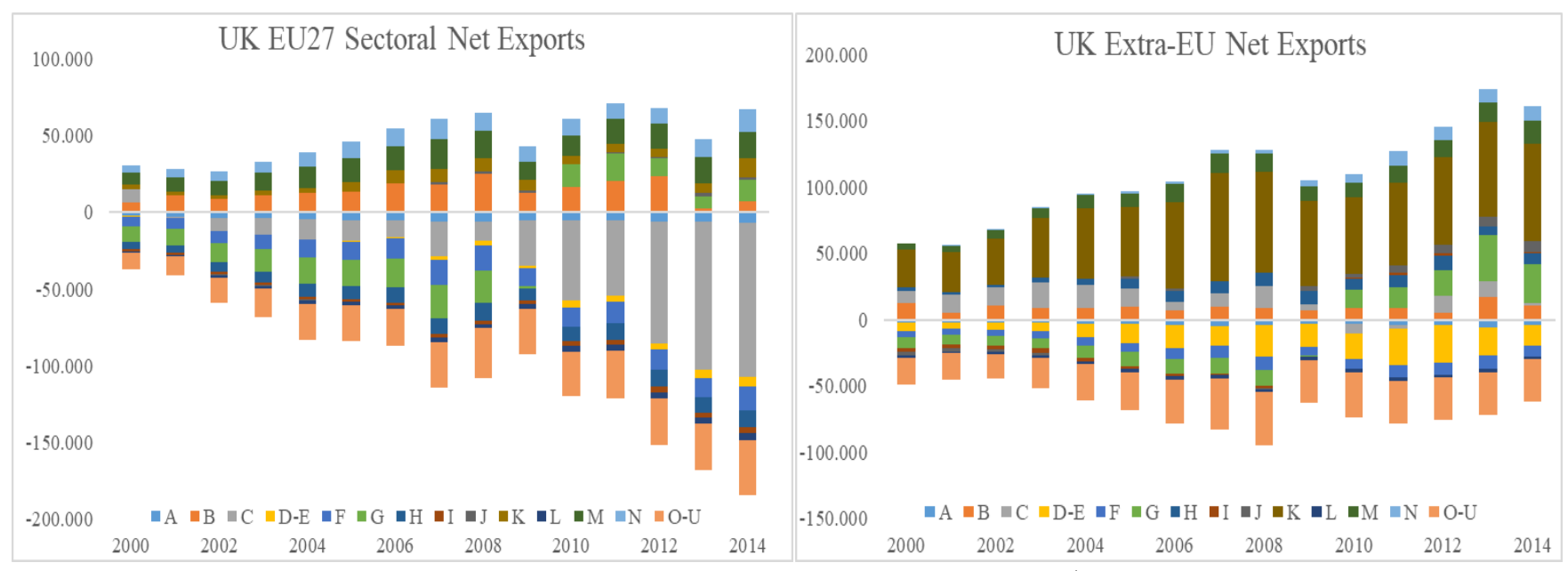

Figure 6. UK sectoral trade balances between 2000 and 2014 by regions (millions of \$). Increasing trade deficits in European manufactured goods $(C)$, have been partly offset by trade surpluses in knowledge-based service sectors $(K, N, M)$ with extraEU countries.

\section{Static Analysis of UK Trade}

Whilst the analysis of time series is useful in understanding developments in the composition of UK trade, the main scope of the present study is to simulate the economic impact of Brexit and historical data would be helpless because cannot incorporate information about such an extraordinary event (Bush and Matthes, 2016). Thus, rather than a structural time series analysis, we prefer a comparative input-output analysis, which also allows us to consider the indirect impact of Brexit by means of global value chains. Therefore, from now on we will focus only on the last available World Input-Output Table provided by the WIOD project (Timmer et al., 2015).

In 2014, Germany and US are respectively the main source and destination country of goods and services, accounting together for 23 percent of the UK's imports and 18 percent of UK's exports (Figure 7). The other top source countries in the EU are France, Netherlands, Ireland, Italy, Belgium and Spain. As to the destination of UK's exports, the same countries are in the top 10 with the exception of Spain and with the addition of Luxembourg, which is one of the leading importers of UK financial services. Outside the EU, beside US, China results one of the best source and destination for UK's goods. UK imports from outside the EU come also from Norway and Switzerland. The latter, as well as Canada, represents a top destination country for UK services, especially financial, while Russia is among the main destination for UK goods.

Analysing the data further to investigate specific sectors, Figure 8 shows the top 10 UK import and export sectors. Whilst the most important imports principally come from the EU, a larger fraction of the top exports goes to extra EU countries. Supporting earlier discussion, the top exports are mostly service industries with Financial, Auxiliary Financial and Administrative Services make up 17 percent of the UK's total exports. Exports are driven by extra EU countries whereas, in line with what above mentioned, the most significant UK's imports are manufactured goods from the EU. The largest imports belongs to motor vehicles sector, food and beverage and transport equipment that together represent 22 percent of total imports.

In Figure 9 the 56 WIOD sectors are grouped into 4 main sectors: Raw material, Manufacturing, Services, Financial (plus final demand), in order to show the UK sectoral overseas trade balance in 2014. Green edges represent surplus relationship whilst red edges depict sectoral deficits. Nodes size is proportional to the amount of money that flows in and out through each sector. The network shows again that the main item of imports of final products is represented by manufacturing goods, coming mainly 
from Germany, China, Italy and other EU countries. The overseas manufacturing plays an important role also in terms of intermediate inputs. Indeed, the UK manufacturing sector has a trade deficit with all the other foreign manufacturing industries, with the exception of Ireland and ROW manufacturing. Other main surplus sources for the UK manufacturing sector are the US Services and ROW Services. This latter represents, actually, an important source of surplus for all the UK sectors.

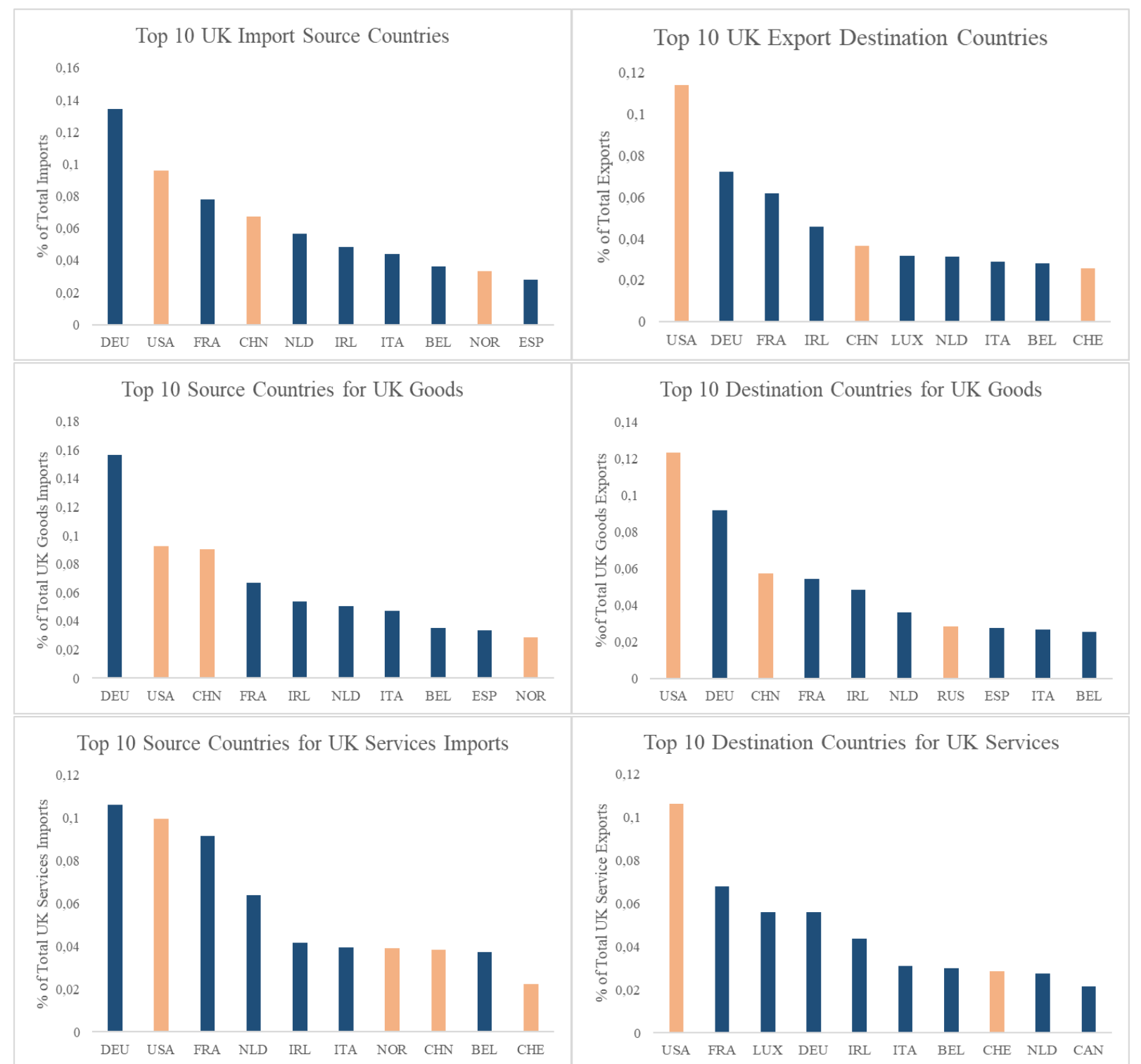

Figure 7. Top 10 import and export countries in total, in goods and in services in 2014. Note: orange shows extra-EU countries. For country codes, see Table A. 1 in Appendix.

The UK Services sector shows massive trade deficits, mostly towards the manufacturing sectors in Germany, China, ROW and ROW Raw material, that are partly covered by income from ROW final demand, and ROW and US Services sectors. The strategic sector in the UK's trade relations is undoubtedly the Financial sector. The UK sectoral and final trade deficits are mainly financed by overseas investment and by the earnings from financial services. Unlike the manufacturing sector, the UK Financial sector shows a surplus with almost all the foreign industries. In particular, the UK financial services records huge surplus towards the Financial and Services ROW sectors, ROW final demand, US Services and 
Luxembourg Financial sector. Finally, the Raw material sector, with respect to the others, plays a much less important role in the UK trade relationships.

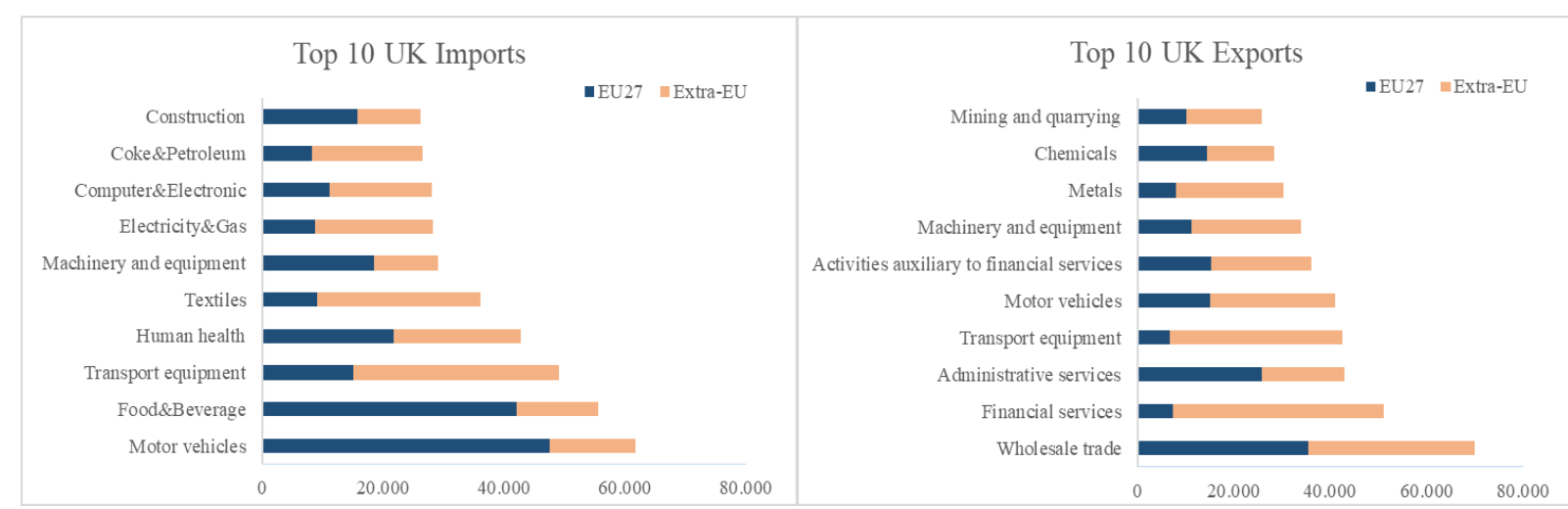

Figure 8. Top 10 imports and exports by sectors in 2014 (millions of \$).

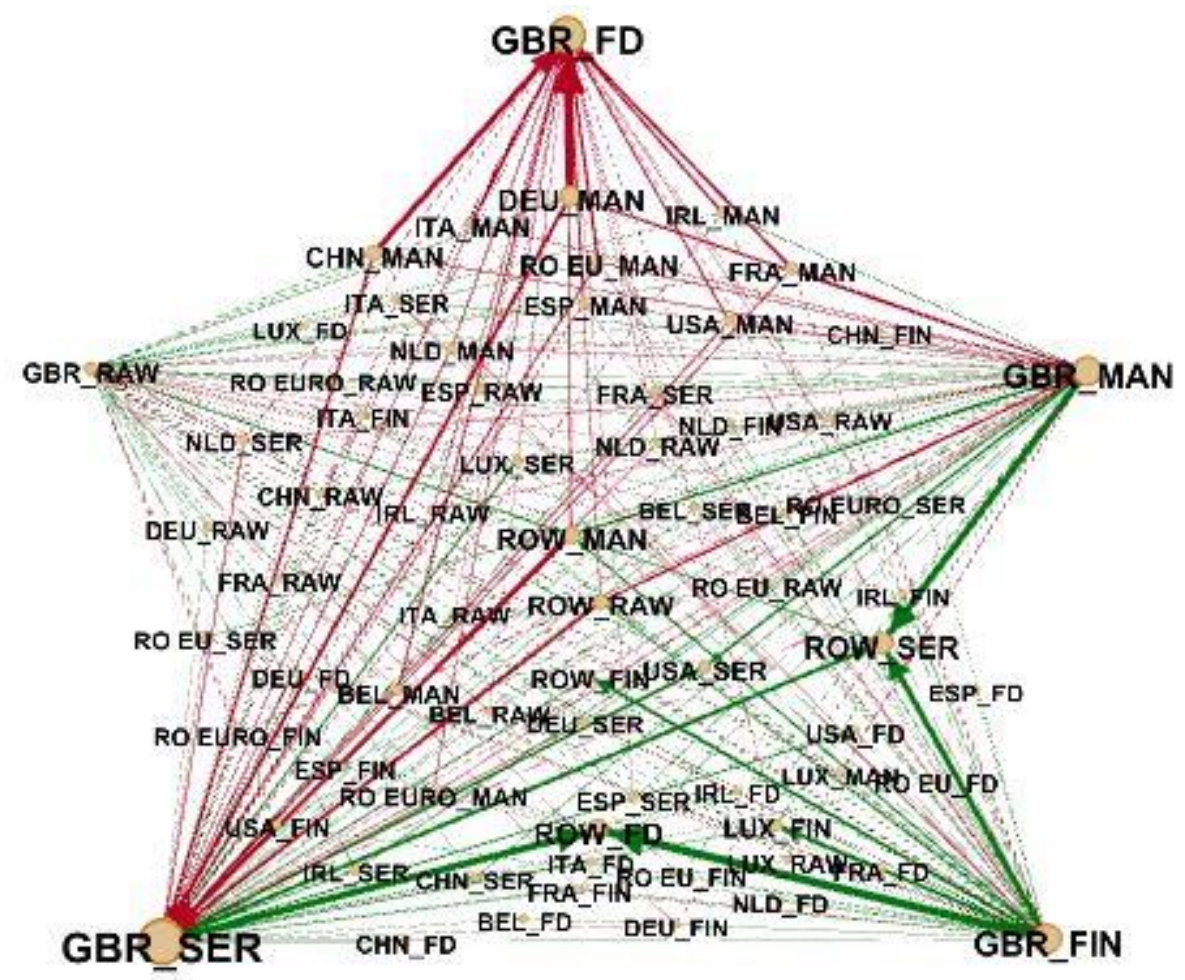

Figure 9. UK trade network. Green edges represent surplus relationship whilst red edges depict sectoral deficits.

Figure 9 provides a simplified version of the inter-sectoral linkages within the UK external production network and suggests that UK is involved in a complex value chains. This remark is supported by the fact that most UK trade is in intermediate inputs rather than final products: 61 percent of UK total trade is, indeed, in intermediate. In particular, 57 percent of UK total imports and 64 percent of UK total exports are intermediate inputs. Therefore, to assess the economic impact of Brexit, one can no longer ignore the relevance of the global value chains in the transmission of shocks. Hence, it is essential starting from an IO framework in order to capture the indirect links via these value chains.

Summarising, in this section we showed that the UK imports a huge amount of goods, mainly manufacturing, and partly covers these imports by exporting services, mainly financial. The primary 
source for goods and services imports is the EU, whilst the exports of both goods and services are destined for extra EU countries. These remarks suggest a relevant exposure for the EU countries to a scenario in which WTO tariff rules apply. If we also consider the high trade integration and interconnection between UK and EU, it would seem that there will be no Brexit winners. However, as we discuss in sections 2.5.1.4, 2.6 and 2.7, some economic policy options seem promising.

\section{An Inter-Country-Input-Output Analysis of Brexit: Model and Methodology}

In this section, the model used to quantify the impact of Brexit on value added is outlined from first principles. This is followed by a discussion of the different elements of the model: the data used; the counterfactual scenarios modelled; the potential tariffs and non-tariff barriers facing the UK post Brexit and the elasticities of sectors/countries in the model.

\subsection{The Model}

\subsubsection{A Two Country Input-Output Example}

This section will offer a basic introduction to IO tables along with an explanation of the foundations of the model in a two country, one sector setting. Overall, this will help the reader to gain an understanding of the matrix algebra involved and will eventually lead on to the next section which explains the $N$ country, $K$ sector model used in the analysis. The notation given in this paper follows most closely that given by Koopman et al. (2014) and Los et al. (2016) .

The WIOD table gives intermediate and final bilateral trade between all countries in the database: it also gives figures for value added and gross output in each country/sector. Figure 10 shows an IO table for a two-country world in which each country produces in a single sector. In the sector, goods can either be consumed as a final product or used as an intermediate input and both countries export intermediate and final goods to the other country. This is shown, along with the value added and gross output for each country in Figure 10. Observing Figure 10, it is clear that all gross output produced in either country is used as an intermediate good or final good, domestically or abroad.

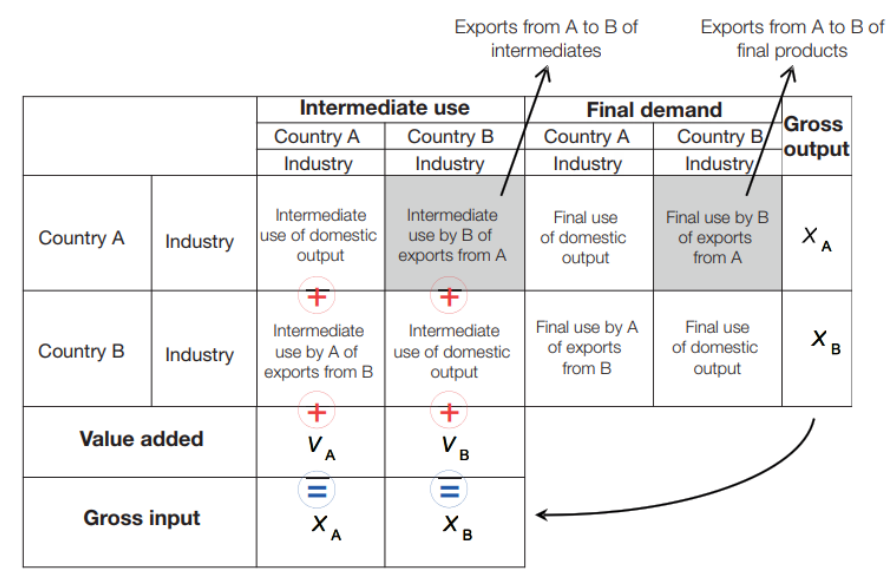

Figure 10. A simple two country, one sector input-output table. Gross output for each country can be calculated by summing domestic and imported intermediate use and value added in each country or by summing total intermediate and final use in each country. Source: UNCTAD (2013).

\footnotetext{
${ }^{b}$ Matrices are indicated by bold capitals, vectors by bold lowercases and scalars by italic lowercases. Diagonal matrices are indicated by a hat over the vector containing the elements on the main diagonal. Primes indicate transposition.
} 
Therefore, country $p$ 's gross output, $x_{p}$, is given by:

$$
x_{p}=a_{p p} x_{p}+a_{p q} x_{q}+f_{p p}+f_{p q} \quad p, q=1,2
$$

where $f_{p q}$ is the quantity of country $p$ 's output consumed as a final good in country $q$ and $a_{p q}$ is the units of intermediate inputs produced in country $p$ needed to produce one unit of the good in country $q$. These are the well-known IO coefficients or technology coefficients that in a multi country IO framework are not only determined by technological input but also by interregional and international trade patterns (W. Chen et al., 2018). The input coefficients can be found by divided the total intermediate use in country $q$ of country $p$ 's product, $z_{p q}$, given in the intermediate section in the IO table, by the gross output of country $p$, that is $a_{p q}=z_{p q} / x_{p}$. Equation (1) can then be written in matrix form as:

$$
\left[\begin{array}{l}
x_{1} \\
x_{2}
\end{array}\right]=\left[\begin{array}{ll}
a_{11} & a_{12} \\
a_{21} & a_{22}
\end{array}\right]\left[\begin{array}{l}
x_{1} \\
x_{2}
\end{array}\right]+\left[\begin{array}{l}
f_{11}+f_{12} \\
f_{21}+f_{22}
\end{array}\right]
$$

which can be summarised as:

$$
\mathbf{x}=\mathbf{A x}-\mathbf{F i}
$$

where $\mathbf{F}=\left[\begin{array}{ll}f_{11} & f_{12} \\ f_{21} & f_{22}\end{array}\right]$ and $\mathbf{i}$ is column vector in which all elements are 1, which when multiplied by $\mathbf{F}$ sums each of the rows in $\mathbf{F}$, as shown in the last component of equation (2). Rearranging equation (2), to make the $\mathbf{x}$ vector the subject, we have:

$$
\left[\begin{array}{l}
x_{1} \\
x_{2}
\end{array}\right]=\left[\begin{array}{cc}
I-a_{11} & -a_{12} \\
-a_{21} & I-a_{22}
\end{array}\right]^{-1}\left[\begin{array}{l}
f_{11}+f_{12} \\
f_{21}+f_{22}
\end{array}\right]=\left[\begin{array}{ll}
b_{11} & b_{12} \\
b_{21} & b_{22}
\end{array}\right]\left[\begin{array}{l}
f_{11}+f_{12} \\
f_{21}+f_{22}
\end{array}\right]
$$

or, more simply:

$$
\mathbf{X}=(\mathbf{I}-\mathbf{A})^{-1} \mathbf{F i}=\mathbf{L F i}
$$

where $\mathbf{L}$ is known as the (global) Leontief inverse matrix. Each element of $\mathbf{L}, l_{p q}$, is a Leontief coefficient and gives the amount of country $p$ 's output required to produce one more unit of the final good in country $q$.

In order to relate equation (5) to the value-added and GDP of each country, the figures of value-added for each country (as given in the last row of Figure 10) are used. The fraction of gross output that represents domestic value-added in country 1 , given as $v_{1}$ is the value-added of country $1, w_{1}$, divided by country 1 's total gross output, that is, $v_{1}=w_{1} / x_{1}$. These are called the value-added coefficients. For ease of future calculation, the value-added coefficient matrix, $\widehat{\mathbf{v}}$, is formed by putting the value-added coefficients on the diagonal elements of the matrix and zeros on the off-diagonals. Therefore:

$$
\widehat{\mathbf{V}}=\left[\begin{array}{cc}
v_{1} & 0 \\
0 & v_{2}
\end{array}\right]
$$

In this two country, one sector model, a country's GDP is, by definition, the total domestic value-added within its gross output which is the total amount paid to all factors of production in each country. We therefore have that, utilising the result of equation (4), each country's GDP is given by: 


$$
\begin{gathered}
{\left[\begin{array}{l}
G D P_{1} \\
G D P_{2}
\end{array}\right]=\left[\begin{array}{cc}
v_{1} & 0 \\
0 & v_{2}
\end{array}\right]\left[\begin{array}{l}
x_{1} \\
x_{2}
\end{array}\right]=\left[\begin{array}{cc}
v_{1} & 0 \\
0 & v_{2}
\end{array}\right]\left[\begin{array}{cc}
I-a_{11} & -a_{12} \\
-a_{21} & I-a_{22}
\end{array}\right]^{-1}\left[\begin{array}{l}
f_{11}+f_{12} \\
f_{21}+f_{22}
\end{array}\right]} \\
=\left[\begin{array}{cc}
v_{1} & 0 \\
0 & v_{2}
\end{array}\right]\left[\begin{array}{ll}
b_{11} & b_{12} \\
b_{21} & b_{22}
\end{array}\right]\left[\begin{array}{l}
f_{1} \\
f_{2}
\end{array}\right]
\end{gathered}
$$

which can be summarised as:

$$
G D P=\widehat{\mathbf{V}} \mathbf{x}=\widehat{\mathbf{V}}(\mathbf{I}-\mathbf{A})^{-\mathbf{1}} \mathbf{F i}=\widehat{\mathbf{V}} \mathbf{L F i}
$$

This is the equation used to calculate the static GDP using the $N$ country, $K$ sector model which will be explained in detail in the next section.

\subsubsection{The N Country, K Sector Model}

When there are multiple sectors and countries, rather than the simple IO table presented in Figure 10, the IO table now has the structure shown in Figure 11. This is a large, complex matrix comprised of individual bilateral matrices that show each country's sectoral trade with each of the other $N-1$ countries in the database.

Now each matrix described in the previous example becomes larger and more complex. Using block matrix notation to show bilateral matrices/vectors, we now have that $\mathbf{x}=(\mathbf{I}-\mathbf{A})^{-\mathbf{1}} \mathbf{F i}$ from equation (5) is given by:

$$
\left[\begin{array}{c}
\mathbf{x}_{1} \\
\mathbf{x}_{2} \\
\vdots \\
\mathbf{x}_{\mathbf{N}}
\end{array}\right]=\left[\begin{array}{cccc}
\mathbf{I}-\mathbf{A}_{11} & -\mathbf{A}_{12} & \ldots & -\mathbf{A}_{1 \mathbf{N}} \\
-\mathbf{A}_{21} & \mathbf{I}-\mathbf{A}_{22} & \ldots & -\mathbf{A}_{2 N} \\
\vdots & \vdots & \ddots & \vdots \\
-\mathbf{A}_{\mathbf{N} 1} & -\mathbf{A}_{\mathrm{N} 2} & \ldots & \mathbf{I}-\mathbf{A}_{\mathrm{NN}}
\end{array}\right]^{-\mathbf{1}}\left[\begin{array}{c}
\sum_{\mathbf{q}}^{\mathbf{N}} \mathbf{F}_{1 \mathbf{q}} \\
\sum_{\mathbf{N}}^{\mathbf{q}} \mathbf{F}_{2 q} \\
\vdots \\
\sum_{\mathbf{N}} \mathbf{F}_{\mathbf{N q}}
\end{array}\right]
$$

With $N$ countries and $K$ sectors. Where $\mathbf{x}_{p}$ is country $p$ 's $K \times 1$ output vector which shows gross output in each of the $K$ sectors in country $p, \mathbf{A}_{p q}$ is the $K \times K$ bilateral coefficient matrix that shows the IO coefficients for the $K$ sectors that country $p$ exports to country $q$ and $\mathbf{F}_{p q}$ is the $K \times 1$ vector that shows final goods produced in $p$ and consumed in $q$. Overall, equation (9) can be summarised, again as in equation (5).

Similarly, we can extend the value-added coefficient matrix given in equation (6) in the two-country example, to calculate the static GDP of the $K$ sectors in the $N$ countries which is given again by the equation (8), with the difference that now the coefficient matrix $\mathbf{A}$ and the final demand matrix $\mathbf{F}$, are partitioned matrices.

$$
G D P_{O}=\widehat{\mathbf{V}}(\mathbf{I}-\mathbf{A})^{-\mathbf{1}} \mathbf{F i}
$$


where $G D P_{O}$ is the $N K \times 1$ vector showing the GDP of each of the $K$ sectors in the $N$ countries. We start from equation (10) to calculate the post-Brexit $G D P_{1}$ for each of the 56 sectors in each of the countries in our dataset. In order to assess the economic impact of Brexit a method called partial extraction is used, which is described in the next section.

\begin{tabular}{|c|c|c|c|c|c|c|c|c|c|c|c|c|c|}
\hline & & & \multicolumn{7}{|c|}{ Use by country-sectors } & \multicolumn{3}{|c|}{ Final Use by countries } & \multirow{3}{*}{$\begin{array}{c}\text { Total } \\
\text { Use }\end{array}$} \\
\hline & & & \multicolumn{3}{|c|}{ Country 1} & \multirow{2}{*}{$\ldots$} & \multicolumn{3}{|c|}{ Country N } & $\begin{array}{c}\text { Country } \\
1\end{array}$ & $\ldots$ & $\begin{array}{c}\text { Country } \\
\mathrm{N}\end{array}$ & \\
\hline & & & $\begin{array}{c}\text { Sector } \\
1 \\
\end{array}$ & $\ldots$ & $\begin{array}{c}\text { Sector } \\
\mathrm{K}\end{array}$ & & $\begin{array}{c}\text { Sector } \\
1 \\
\end{array}$ & $\ldots$ & $\begin{array}{c}\text { Sector } \\
\mathrm{K}\end{array}$ & & $\ldots$ & & \\
\hline \multirow{7}{*}{$\begin{array}{l}\text { Supply } \\
\text { from } \\
\text { country- } \\
\text { sectors }\end{array}$} & \multirow{3}{*}{$\begin{array}{c}\text { Country } \\
1\end{array}$} & Sector 1 & & & & & & & & & & & \\
\hline & & $\ldots$ & & & & & & & & & & & \\
\hline & & Sector K & & & & & & & & & & & \\
\hline & $\ldots$ & & & & & & & & & & & & \\
\hline & \multirow{3}{*}{$\begin{array}{c}\text { Country } \\
\mathrm{N}\end{array}$} & Sector 1 & & & & & & & & & & & \\
\hline & & $\ldots$ & & & & & & & & & & & \\
\hline & & Sector K & & & & & & & & & & & \\
\hline \multicolumn{10}{|c|}{ Value Added } & & & & \\
\hline \multicolumn{3}{|c|}{ Gross Output } & & & & & & & & & & & \\
\hline
\end{tabular}

Figure 11. An $N$ country $K$ sector IO table. Similar to Figure 10, the gross output of each sector in each country can be found by summing the values in each row or column. Source: Timmer et al. (2015).

\subsubsection{The Partial Extraction Method in the Case of a Trade Shock}

Building on Los et al. (2016) work, W. Chen et al. (2018) employ the hypothetical extraction method in order to estimate the share of GDP exposed to Brexit for EU regions. In the traditional IO literature, the objective of the hypothetical extraction approach is to quantify how much the total output of an $n$-sector economy would be affected by the removal of a particular $j$ sector from that economy (further details in Miller, 1966; Miller and Lahr, 2001 and Miller and Blair, 2009). Dietzenbacher et al. (1993), instead of extract one sector from a sector-based model, consider the effects of hypothetically extracting a region from a many-region model. Similarly, W. Chen et al. (2018) hypothetically extract the trade between UK and EU regions. In their paper, the authors set certain elements of the coefficient $\mathbf{A}$ matrix and the final demand $\mathbf{F}$ matrix to zero to create a hypothetical world in which region $(p)$ does not export anything to region $(q)$, while leaving the rest of the economic structure of the world unaffected. That is, they set the coefficients that represent exports from region $p$ to region $q$ to zero. Using the modified matrices, denoted $\mathbf{A}^{\#}$ and $\mathbf{F}^{\#}$, they calculate the new hypothetical GDP given as:

$$
G D P^{\#}=\widehat{\mathbf{V}}\left(\mathbf{I}-\mathbf{A}^{\#}\right)^{-\mathbf{1}} \mathbf{F}^{\#} \mathbf{i}
$$

The authors then calculate the effect of the hypothetical trade change in the A and $\mathbf{F}$ matrices on GDP, using equations (10) and (11) they calculate:

$$
D V A^{\#}=G D P_{O}-G D P^{\#}
$$

This gives the change in value-added as a result of the hypothetical reduction in exports. In this paper, we build on the extraction method employed in Los et al. (2016) and W. Chen et al. (2018), adopting the socalled partial extraction method introduced by Dietzenbacher and Lahr (2013). In their explanation of the partial extraction method, Dietzenbacher and Lahr (2013) assume that an establishment of an industry, 
consisting of a number of identical establishments, ceases to exist so that the industry capacity reduces. In this case, a total extraction (nullification) will not occur, simply the intermediate and final deliveries sold by this industry, decrease by a percentage $\alpha \cdot 100 \%$. Hence, the new coefficient will be equal to $a_{k j}^{*}=z_{k j}^{*} / x_{j}=(1-\alpha) z_{k j}^{*} / x_{j}=(1-\alpha) a_{k j}$ and the new final demand will be equal to $f_{k}^{*}=(1-$ a) $f_{k}{ }^{c}$. Similarly, in this study, rather than setting elements of the $\mathbf{A}$ and $\mathbf{F}$ matrices equal to zero (as in W. Chen et al. 2018), an import demand function is used to predict how import demand between the UK and the EU will change post-Brexit. This change is then applied to elements of the $\mathbf{A}$ and $\mathbf{F}$ matrices to calculate the new GDP post-Brexit. This is explained in detail below.

Let us consider a simple import demand function (Thirlwall, 1979) for a specific commodity in a specific country:

$$
M_{i}=\left(\frac{e P_{F i}}{P_{i}}\right)^{\varepsilon_{D i}} Y_{D} \eta_{D i}
$$

where $M_{i}$ is the domestic import demand for commodity $i, e$ is the exchange rate, $P_{F i}$ is the foreign price for commodity $i, P_{i}$ is the domestic price of commodity $i, \varepsilon_{D i}<0$ is the domestic relative price elasticity of commodity $i, Y_{D}$ is domestic income and $\eta_{D i}>0$ is the income elasticity of demand for imports of commodity $i$. This suggests that the volume of imports of commodity $i$ demanded is a combination of these variables. In order to find the change in demand over time, the natural logarithms of equation (13) are taken and the equation is differentiated with respect to time:

$$
\dot{M}_{l}=\varepsilon_{D i}\left(\dot{e}+\dot{P}_{F l}-\dot{P_{l}}\right)+\eta_{D i} \dot{Y}_{D}
$$

where $\dot{x}=\frac{\partial \ln x}{\partial t}$. Assuming that $e, P_{i}$ and $Y_{D}$ are fixed, import demand is given solely by the relative price elasticity, $\varepsilon_{D i}$ and the foreign price for commodity $i, P_{F i}$ :

$$
\dot{M}_{\iota}=\varepsilon_{D i} \dot{P_{F l}}
$$

Following on from the assumption that $P_{i}$ is fixed, we also assume that the only channel by which the foreign price of commodity $i$ can change is through the introduction of new post-Brexit tariffs (or an increase in NTBs) on the commodity. Therefore, the change in import demand between the UK and the EU is simply given by:

$$
\dot{M}_{l}=\varepsilon_{D i} \tau_{i}
$$

Where $\tau_{i}$ is the post-Brexit EU tariffs (plus NTBs) on sector $i$ and $\varepsilon_{D i}$ is the import elasticity of sector $i$ in the domestic country. Since elasticities are always negative, any increase in tariffs results in a reduction of import demand. Since the WIOD only gives data on sectors not specific commodities, equation (16) is the change in demand for all the products of a specific sector $i$, in a particular country (given as $D$ ).

We assume that both intermediate and final import demands for goods and services respond negatively to foreign price increases. Equation (16) is then split in two reduced equations. The intermediate (17) and final (18) import demand functions:

\footnotetext{
${ }^{\mathrm{c}}$ In their model 3 Alatriste-Contreras and Fagiolo (2014) present a similar approach to explain the propagation of economic shocks in Input-Output networks.
} 


$$
\begin{aligned}
& i \dot{m}_{\imath}=\varepsilon_{D i} \tau_{i} \\
& f \dot{m}_{\imath}=\varepsilon_{D i} \tau_{i}
\end{aligned}
$$

which are then used to alter elements of the $\mathbf{A}$ and $\mathbf{F}$ matrices to take into account the tariffs and NTBs post-Brexit.

The elements of the matrices that are altered are any elements which involve interaction between the UK and the EU. To aid understanding, consider a three country, one sector IO model, the three countries/regions being the UK (G), EU (E) and ROW (R). The A and F matrices for this model will be given as:

$$
\mathbf{A}=\left[\begin{array}{lll}
a_{G G} & a_{G E} & a_{G R} \\
a_{E G} & a_{E E} & a_{E R} \\
a_{R G} & a_{R E} & a_{R R}
\end{array}\right] \quad \mathbf{F}=\left[\begin{array}{ccc}
f_{G G} & f_{G E} & f_{G R} \\
f_{E G} & f_{E E} & f_{E R} \\
f_{R G} & f_{R E} & f_{R R}
\end{array}\right]
$$

where $a_{p q}$ gives the units of intermediate goods produced in country $p$ needed to produce one unit of the good in country $q$, or alternatively, the import demand in country $q$ for intermediate goods produced in country $p$. Similarly, $f_{p q}$ is the quantity of final products produced in country $p$ demanded in country $q$, or the import demand in country $q$ for final products produced in country $p$. So, in this three-country example, the elements that involve interaction between the UK and the EU will be affected by tariffs post Brexit, namely, the elements $a_{G E}, a_{G U}, f_{G E}$ and $f_{E G}$. Using equations (17) and (18) we know that import demand for UK products in the EU and EU products in the UK will change by the trade elasticity of demand in the respective country-sector, $\varepsilon_{D i}$ multiplied by the new sectoral tariffs in each country $\tau_{i}$, given by $i \dot{m}_{l}$ and $f \dot{m}_{l}$. Since there is only one sector in each country, the modified $\mathbf{A}$ and $\mathbf{F}$ matrices are then:

$$
\mathbf{A}^{*}=\left[\begin{array}{ccc}
a_{G G} & \boldsymbol{a}_{\boldsymbol{G E}}{ }^{*} & a_{G R} \\
\boldsymbol{a}_{\boldsymbol{E G}}{ }^{*} & a_{E E} & a_{E R} \\
a_{R G} & a_{R E} & a_{R R}
\end{array}\right] \quad \mathbf{F}^{*}=\left[\begin{array}{ccc}
f_{G G} & \boldsymbol{f}_{\boldsymbol{G E}}{ }^{*} & f_{G R} \\
\boldsymbol{f}_{\boldsymbol{E G}}{ }^{*} & f_{E E} & f_{E R} \\
f_{R G} & f_{R E} & f_{R R}
\end{array}\right]
$$

where $a_{p q}{ }^{*}=a_{p q}+i m_{p}$ and $f_{p q}{ }^{*}=f_{p q}+f m_{p}$.

This method can then be extended to the $N K \times N K$ coefficient matrix $\mathbf{A}$ and $N K \times N$ final demand matrix $\mathbf{F}$ used in our 56 sector 18 country model, which are shown in equation (9). Using these matrices those elements that show interaction between UK and EU countries are extracted and adjusted as in the previous 3 country example, according to equations (17) and (18). The modified $\mathbf{A}$ and $\mathbf{F}$ matrices are then employed to calculate the new post-Brexit GDP for each sector in each country:

$$
G D P^{*}=\widehat{\mathbf{V}}\left(\mathbf{I}-\mathbf{A}^{*}\right)^{-\mathbf{1}} \mathbf{F}^{*} \mathbf{i}
$$

where $G D P^{*}$ is the $N K \times 1$ vector showing the post-Brexit GDP of each sector in each country and the other elements are defined in equations (9) and (11). Following Los et al. (2016), and using the original GDP given in equation (10), the change in value-added as a result of Brexit can be calculated as:

$$
D V A^{*}=G D P_{O}-G D P^{*}
$$


where $D V A$ is the $N K \times 1$ vector with each element showing the change in value-added as a result of Brexit in all $K$ sectors in all $N$ countries. Considering that this difference is negative by construction, we define $D V A^{*}$ as the absolute loss in value-added (LiVA) and the percentage change $\left(G D P_{O}-G D P^{*}\right) / G D P_{O}$ as the relative LiVA.

\subsubsection{Hypothetical Expansion in the Case of Domestic Import Substitution and Trade Diversion}

Following the literature, our first model interprets Brexit as a trade shock. The theoretical framework of a trade shock model, predicts that an increase in import tariffs will result in production losses all along the supply chain (Dhingra et al., 2017; Vandenbussche et al., 2017; Noguera, 2012). Specifically, the increase in prices due to the introduction of tariffs and non-tariff barriers between the UK and EU would translates in a collapse of respective exports (Baldwin, 2016). With these premises, many Brexit studies, have predict a deep drop of UK's exports to EU and a relative crash of GDP. These predictions, however, depend largely on two key convictions. The first is that the economic performance of the UK improved appreciably after joining the EU (Crafts, 2016; Kierzenkowski et al., 2016). Therefore, leaving the EU would be risky and costly for the UK. However, in a recent study, Gudgin et al. (2017a) question this claim, showing that there is no clear evidence that joining the EU improved the rate of economic growth in the UK. Furthermore, the authors show that the impact of EU membership on the level of exports to the EU is much smaller for the UK than for other EU members (these last two remarks have been also stressed, and predicted by Thirlwall, 2001). The implication would be that the EU membership has fostered the growth of the UK trade deficit with Europe. This trend has led to widespread calls for rebalancing the economy (Coutts and Rowthorn, 2013), and helped to spread a feeling of intolerance towards Europe, which resulted in the victory for the Leave campaign (Los et al., 2017). Indeed, a number of empirical papers show that the support for the Leave option in the Brexit referendum can be labelled as a rejection of globalisation (Rodrik, 2018a; Colantone and Stanig, 2018).

These findings bring us to the second belief behind the results of standard trade shock models. As we mentioned the underlying claim of these models is that trade liberalisation increases welfare. Therefore, any free trade restriction would generate a welfare loss. On the other hand, as well explained by Rodrik (2018a) trade liberalisation generically produces losers and the simple economics of globalisation is bound to intensify inequality of income because it often leads to increased market failures. Indeed, 'compensation' cannot credibly address the longer-term erosion of distributional bargains entailed in trade agreements and financial globalisation. Therefore, trade liberalisation is not necessarily auspicious; rather, under circumstances of weak domestic growth trade protectionism policies would be preferable (Rodrik, $2018 b, 2018 \mathrm{c})$. The debate about free trade or protection is controversial and unsolved, but this is not the place to deepen the topic. What is noteworthy is that these last remarks question the usual conclusion of standard trade models, according to which Brexit surely will result in great losses for the UK. Thus, one would wonder: are there any political alternatives that would allow the UK to take advantage of Brexit?

In line with Rodrik observations, one can consider Brexit as a special case in which a country implements a protectionist trade policy in order to rebalance the external accounts and boost domestic growth. Indeed, sooner or later a country whose balance of payments is habitually adverse will have to get its spending in balance with its income (Stone 1970). This means that it will have to export more in relation to its imports. However rather than trade policies, the typical intervention to balance a country's external accounts is currency devaluation. This is also the case for the UK which has manipulated the real exchange rates in order to boost exports, curb imports and counter the current recession (Gagnon, 2013; Joyce et al. 2011). Nevertheless, the UK external deficit persists and the domestic economy has not improved significantly. One reason behind the ineffectiveness of pound depreciation is that the price 
elasticity of demand for UK exports is low. Thus, as pointed out by Aiello et al. (2015), the level of UK exports appears to be unrelated to the real exchange rate for the UK.

According to Skidelsky (2016) in such circumstances, the solution would be the substitution of goods currently imported with domestically produced goods. Indeed, as Godley and May (1977) find, the economic gain brought about by import restrictions is extremely large compared with a policy of devaluation, particularly in the short run. The trade and economic scheme, which advocates replacing foreign imports with domestic production, is known as import substitution. This policy has been the object of a long and popular debate among economists in the late 20th century, and especially in the UK (see Bruton, 1998; Norman, 1996; Cripps and Godley, 1976, Greenaway, 1983 and Greenaway and Milner, 2003 for further insight). The rest of this section aims to give a simplified exposition of the implications of this alternative trade strategy within an Inter-Country-Input-Output framework.

To the best of our knowledge, so far the analysis of import (and export) substitution in IO schemes has occurred, substantially, considering a national economy, more than in multi-regional or multi-country schemes. Furthermore, this literature has been mainly focused on measuring the trend of import substitution starting from structural accounting exercises, rather than hypothesizing changes in the structure and assessing its consequences through scenarios (Desai, 1969; Balassa, 1979). One exception is provided by Richard Stone (1970) that proposes a model in which a change in the coefficient matrix (A) is assumed in the face of a substitution of imported intermediate inputs for households and recalculates the aggregate consistency of the whole IO system (solving the problems linked to changes in value added, etc.). However, here we refer again to Dietzenbacher and Lahr (2013) as benchmark. In their last section, the authors briefly explain that the partial extraction method works equally well in cases where coefficients increase in magnitude (or where some increase while others decrease). Such a manipulation is labelled as hypothetical expansion and provides that the new coefficient will be equal to $a_{k j}^{*}=z_{k j}^{*} / x_{j}=$ $(1+\alpha) z_{k j}^{*} / x_{j}=(1+\alpha) a_{k j}$ and the new final demand will be equal to $f_{k}^{*}=(1+\alpha) f_{k}$.

Building on the intuition of Dietzenbacher and Lahr (2013), in our second Brexit model we consider the case in which the UK substitutes imports from EU with domestically or extra-EU produced products. At the same time, we also allow EU countries to substitute imports from UK with products from other EU countries. Hence, in a post-Brexit world, we take into account that both regions, the UK and EU may divert their trade. Indeed, under Brexit, the only tariffs that are likely to be imposed are on products traded between the UK and EU. This means that the tariffs the UK imposes on its extra-EU trade partners will not change. Hence, as pointed out by Dhingra et al. (2017) and Vandenbussche et al. (2017), the extraEU goods will become relatively less expensive for the UK as well as the EU goods will become relatively less expensive among EU countries. The reason is that Brexit actually decreases the relative UK-extraEU and EU-EU trade costs compared to UK-EU trade costs. Therefore, some trade will be diverted from the UK-EU channel to UK-extra-EU and EU-EU. The model can be summarised as follow. We assume that firms would leave fixed the amount of intermediate inputs and unaltered the production lines. Equally, the final consumption is left fixed. Hence, let us consider a column of the coefficient matrix A, with intermediate deliveries. For example, car production in Germany. It needs many inputs one of them is steel. We keep to total input of steel fixed. Then we replace some of the inputs of UK steel by steel from other EU countries. The same is done for the final demands of Germany. We leave the final consumption unchanged, assuming, for example, that German consumers buying less UK clothes and more clothing from other EU countries. Of course, we handle the production processes in the UK in a similar way, replacing French inputs (or final products) by UK, US, China and ROW inputs (or final products). The assumption that only the UK will substitute some imports with domestic products is based on two main reasons. First, in line with the trade shock model we assume that UK exports to 27 countries will be reduced and this will bring about the formation of excess inventory. Second, leaving the EU, the UK would be able to implement a policy that favours the consumption of some of these inventories. In 
contrast, the reduction of exports for EU countries is not prominent as in the UK. Furthermore, European treaties do not allow the protection of domestic goods, but rather encourage the free movement of goods. Hence summarising, in the UK: domestic, US, China and ROW intermediate and final products, will replace some imports from EU. On the other side of the Channel, EU countries will replace some UK inputs and final products with intra-EU purchases. How do these substitutions take place? We assume that input and final consumption source shares remain constant after Brexit. For example, let us consider only intermediate deliveries. Suppose that the reduction of European steel in the UK car production process is $\$ 150$. Looking at the coefficient matrix, we calculate the amount of steel used in the car production process in the UK, coming from the UK, US, China and ROW. Suppose that the UK car sector employs $30 \%$ of UK steel, $15 \%$ of US steel, $35 \%$ of Chinese steel and $20 \%$ of steel from ROW. Thus, we imagine that European steel will be replaced in UK by $\$ 45$ of UK steel, $\$ 22.5$ of US steel, $\$ 52.5$ of Chinese steel and $\$ 30$ of steel from ROW. On the other hand, suppose that the reduction of UK steel in Germany car production process is $\$ 30$. Looking at the coefficient matrix, we calculate the amount of steel used in the car production process in Germany, coming from all the EU countries. Suppose that German car sector employs 30\% of Spanish steel, 15\% of Belgian steel, 10\% of Italian steel, 5\% of French steel, $10 \%$ of Portuguese steel, $10 \%$ of Irish steel, and $20 \%$ from Poland. Thus, we suppose that UK steel will substitute in Germany by $\$ 9$ of Spanish steel, $\$ 4.5$ of Belgian steel, $\$ 3$ of Italian steel, $\$ 1.5$ of French steel, $\$ 3$ of Portuguese steel, $\$ 3$ of Irish steel and $\$ 6$ of steel from Poland.

The aforementioned example can be formalised as follows. Adding another EU country (U) to the three-country one sector model in equations (19) and (20), let us suppose that the modified $\mathbf{A}$ and $\mathbf{F}$ matrices, which take into account the effect of Brexit are given as:

$$
\mathbf{A}^{*}=\left[\begin{array}{cccc}
a_{G G} & \boldsymbol{a}_{\boldsymbol{G E}}{ }^{-} & \boldsymbol{a}_{\boldsymbol{G U}}{ }^{-} & a_{G R} \\
\boldsymbol{a}_{\boldsymbol{E G}}{ }^{-} & a_{E E} & a_{E U} & a_{E R} \\
\boldsymbol{a}_{\boldsymbol{U G}}{ }^{-} & a_{U E} & a_{U U} & a_{U R} \\
a_{R G} & a_{R E} & a_{R U} & a_{R R}
\end{array}\right] \quad \mathbf{F}^{*}=\left[\begin{array}{cccc}
f_{G G} & \boldsymbol{f}_{\boldsymbol{G E}}{ }^{-} & \boldsymbol{f}_{\boldsymbol{G U}}{ }^{-} & f_{G R} \\
\boldsymbol{f}_{\boldsymbol{E G}}{ }^{-} & f_{E E} & f_{E U} & f_{E R} \\
\boldsymbol{f}_{\boldsymbol{U G}}- & f_{U E} & f_{U U} & f_{U R} \\
f_{R G} & f_{R E} & f_{R U} & f_{R R}
\end{array}\right]
$$

where $a_{p q}{ }^{*}=a_{p q}+i \dot{m}_{p}, f_{p q}{ }^{*}=f_{p q}+f \dot{m}_{p}$ and the negative superscripts mean partially extractions. Focusing on the UK, the country-sector substitution coefficient for intermediate and final goods will be equal respectively to:

$$
\begin{gathered}
i s_{G G}=-\frac{a_{G G}\left(i \dot{m}_{E G}+i \dot{m}_{U G}\right)}{a_{G G}+a_{R G}} \\
f s_{G G}=-\frac{f_{G G}\left(f \dot{m}_{E G}+f \dot{m}_{U G}\right)}{f_{G G}+f_{R G}}
\end{gathered}
$$

Therefore, the new coefficient $a_{G G}^{*}$ will be equal to $a_{G G}+i s_{G G}$ and the new final demand $f_{G G}^{*}$ will be equal to $f_{G G}+f s_{G G}$. Adding all the hypothetical expansions to the $\mathbf{A}^{*}$ and $\mathbf{F}^{*}$ matrices we finally get:

$$
\mathbf{A}^{\mathrm{s}}=\left[\begin{array}{cccc}
\boldsymbol{a}_{\boldsymbol{G G}}{ }^{+} & \boldsymbol{a}_{\boldsymbol{G E}}{ }^{-} & \boldsymbol{a}_{\boldsymbol{G U}}{ }^{-} & a_{G R} \\
\boldsymbol{a}_{\boldsymbol{E G}}{ }^{-} & a_{E E} & \boldsymbol{a}_{\boldsymbol{E U}}{ }^{+} & a_{E R} \\
\boldsymbol{a}_{\boldsymbol{U G}}{ }^{-} & \boldsymbol{a}_{\boldsymbol{U} \boldsymbol{E}}{ }^{+} & a_{U U} & a_{U R} \\
\boldsymbol{a}_{\boldsymbol{R} \boldsymbol{G}^{+}} & a_{R E} & a_{R U} & a_{R R}
\end{array}\right] \quad \mathbf{F}^{\mathrm{s}}=\left[\begin{array}{ccccc}
\boldsymbol{f}_{\boldsymbol{G G}}{ }^{+} & \boldsymbol{f}_{\boldsymbol{G E}}{ }^{-} & \boldsymbol{f}_{\boldsymbol{G U}}{ }^{-} & f_{G R} \\
\boldsymbol{f}_{\boldsymbol{E G}}{ }^{-} & f_{E E} & \boldsymbol{f}_{\boldsymbol{E U}}{ }^{+} & f_{E R} \\
\boldsymbol{f}_{\boldsymbol{U G}}{ }^{-} & \boldsymbol{f}_{\boldsymbol{U E}}{ }^{+} & f_{U U} & f_{U R} \\
\boldsymbol{f}_{\boldsymbol{R} \boldsymbol{G}}{ }^{+} & f_{R E} & f_{R U} & f_{R R}
\end{array}\right]
$$


The column sums of these new matrices are equal to the column sums of the pre-Brexit $\mathbf{A}$ and $\mathbf{F}$ matrices, which means that the change in import demand in the UK for EU products is replaced by the same amount, with products from UK and ROW industries. Similarly, the change in import demand in the EU countries for UK products is replaced by the same amount, with products from other EU countries. The four-country one sector model can be extended to the $N K \times N K$ matrices used in the analysis as given in equation (9). Using these new matrices, it is then possible to calculate the new GDP as a result of import substitution and trade diversion policies:

$$
G D P^{s}=\widehat{\mathbf{V}}\left(\mathbf{I}-\mathbf{A}^{\mathbf{s}}\right)^{-\mathbf{1}} \mathbf{F}^{\mathbf{s}} \mathbf{i}
$$

This can then be used to find the country-sector absolute loss in value-added:

$$
L i V A^{S}=G D P_{O}-G D P^{s}
$$

and the relative LiVA as the fraction $L i V A^{S} / G D P_{O}$.

\subsection{Methodology}

\subsubsection{Data}

The data used is the WIOD database, which is described in detail in the previous section. This database provides information on bilateral trade and global value chains of 44 countries, including one rest of the world (ROW) estimate. Values are given for 56 goods and services sectors with the most recent year being 2014. For our analysis, the database remained at the 56-sector level but was condensed into 18 countries/regions, for details of these and WIOD country codes see Table A.1 in the Appendix.

\subsubsection{Counterfactual Scenarios}

As outlined previously, this paper considers two counterfactual scenarios, a soft and a hard Brexit as outlined in Dhingra (2017). In the soft Brexit scenario, the UK remains in the single market and therefore there are no tariffs on goods traded between the UK and the EU. In the hard Brexit scenario, the UK does not establish a trade deal with the EU, leaves the single market and the UK and the EU trade under WTO terms, each applying MFN tariffs. These are the tariffs that WTO members must apply when trading with other WTO members (with whom they do not have some form of preferential trade arrangement). Like Dhingra et al. (2017), it is assumed that the UK applies the same MFN tariffs as the EU post-Brexit.

\subsubsection{Tariffs}

This section offers a detailed analysis of any tariff changes that the UK and EU could face post-Brexit. In particular, in the hard Brexit scenario, in which the UK will be forced to trade with the EU according to MFN tariffs. To find the MFN tariffs imposed by the EU, EU tariff data was downloaded from the WTO Integrated Database (IDB). Individual product tariffs were then aggregated into sectors according to the Reference and Management of Nomenclatures (RAMON) classification, this allowed for the conversion of six-digit product codes (given in the WTO data) from the Harmonized Commodity Description and Coding System (HS 2007) to the Statistical Classification of Products by Activity in the European 
Economic Community (CPA 2008) system whose product codes' first two digits correspond to the WIOD sectoral classification.

Figure 12 summarises the EU sectoral tariffs. Due to downward pressure on tariffs across the WTO in the past 20 years, EU tariffs are relatively low for many sectors although remain high for some. Food, Beverage and Tobacco faces the highest tariffs, with an average sector tariff of $10 \%$ and a maximum sector tariff of $74.9 \%$ for the import of Tobacco. Agriculture and Fishing also faces high tariffs, particularly for the trade of animal and dairy products. Other sectors facing high tariffs are Textiles and Motor Vehicles with average tariff rates of 8.2 and 6.4, respectively. Earlier analysis in section 4 of this paper (Figure 8) showed that Food, Beverage and Tobacco, Textiles and Motor Vehicles were amongst the UK's most imported sectors from the EU. This suggests that those sectors that the UK relies most heavily on for EU imports will also face the highest tariffs.

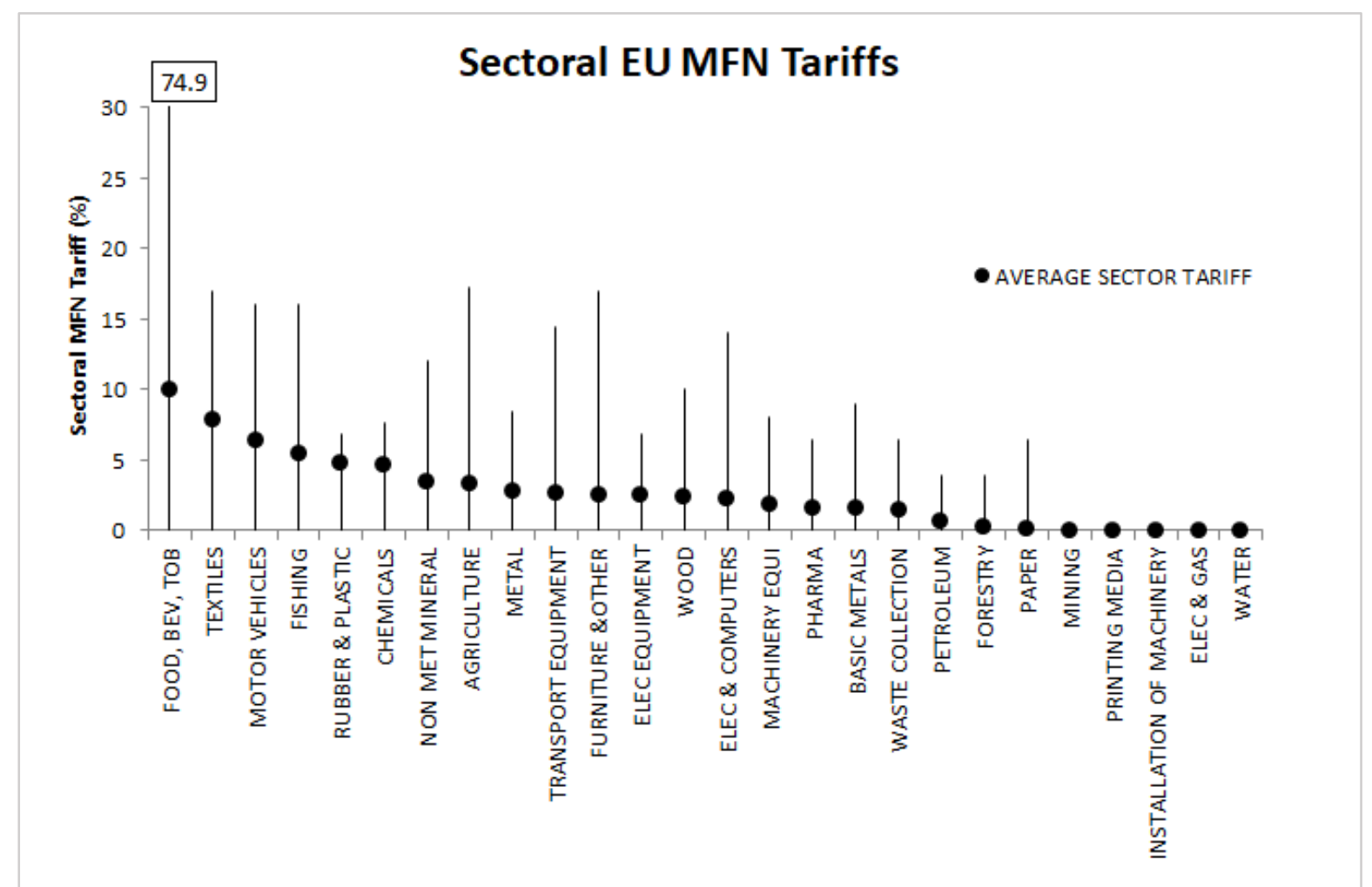

Figure 12. EU MFN Tariffs facing the UK in hard Brexit scenario. Note: The upper and lower bounds correspond to the lowest and highest tariff values in each sector. Dots show the unweighted average tariff in each sector, which will be used in the analysis.

\subsubsection{Non-Tariff barriers}

In all scenarios, there will be an increase in non-tariff barriers (NTBs) given a more distant relationship with the EU, post-Brexit. We use the NTBs given by Dhingra (2017) in our analysis. The authors use estimates of tariff equivalents of NTBs, given by Berden et al. (2009) between the US and the EU. Since it is unlikely that the UK will face the same barriers than the US, in the optimistic scenario the UK face $1 / 4$ of the non-tariff barriers faced by the US, whilst in the pessimistic scenario, the UK will face $3 / 4$ of the non-tariff barriers. In the hard Brexit scenario, these non-tariff barriers are summed with the tariffs as outlined in the previous section to provide $\tau_{i}$, the expected change in the price of trade, in equations (17) 
and (18). In the soft Brexit scenario, the only increase in trade costs are the NTBs, therefore, $\tau_{i}$ represents the increase in NTBs. This information is summarised below in Figure 13.

Soft Brexit

$0 \%$

$2.77 \%$
Hard Brexit

MFN tariff

$8.31 \%$

Figure 13. Summary of tariffs and NTBs in soft and hard Brexit scenarios.

\subsubsection{Elasticity}

Tariffs increase the prices of goods and services crossing borders, as a result, the demand for these goods and services can change. The responsiveness of import and export demand to changes in the price of trade are known as trade elasticities. Imbs and Mejean (2017) provide a comprehensive list of sector/country specific trade elasticities for 28 developed and developing countries, showing that trade elasticities vary greatly across different countries and sectors. Hence, it is important to include heterogenous elasticities in the analysis. They do not provide elasticities for all the sectors/countries in our database. Therefore, following Vandenbussche et al. (2017) for sectors of which no elasticity value is provided, an elasticity of -4 is used, which is a lower end estimate of the trade elasticity. These are the trade elasticities used to provide value $\varepsilon_{D i}$ in equations (17) and (18).

\section{Results}

In this section, we present the soft and hard Brexit results related to the trade shock model and to the domestic import substitution and trade diversion model.

\subsection{Trade Shock Model Results}

Table A. 2 in the Appendix presents the LiVA for all 18 countries in the dataset, in all four scenarios. The results for the trade shock model soft and hard scenarios are summarised in figures 14 and 15. Table A.2 and figures 14 and 15 aggregate the results for the 27 countries within the EU (excluding the UK), presented as EU27. In order to find LiVA for a country as whole, individual sector losses were summated. In Table A.2, we provide the LiVA both in absolute terms and as a percentage of each country/sectors original value added. W. Chen et al. (2018) use the relative LiVA as an indicator of domestic value added exposed to the negative trade-related consequences of Brexit. Here the relative LiVA allows for an understanding of the relative effect of value added losses on sectors/countries, relative to the size of the sector/country.

The results showed in figures 14 and 15 suggest that the UK will be among those countries that are hit hardest in absolute and relative terms. Estimated LiVA in the UK ranging from $\$ 36$ billion in the soft Brexit scenario to $\$ 135$ billion in the hard Brexit scenario. This corresponds to a drop in value added production as percentage of GDP of 1.35 percent under a soft Brexit and up to 5.07 percent under a hard Brexit scenario. Whilst the UK is the most affected individual country, when aggregating the EU27, as a region, the EU27 faces larger absolute losses than the UK, namely $\$ 55$ billion and \$219 billion in the soft and hard scenarios respectively. These losses, however, are due to EU27 size as they constitute only 0.39 
percent and 1.57 percent of the EU27's original value added. The absolute and relative LiVA differ substantially across EU27 member states. The most affected EU27 countries in terms of absolute losses are Germany, France, Italy, the Netherlands and the region we labelled Rest of Europe, for both the soft and hard Brexit scenarios. The picture is not so different if we consider the relative LiVA. EU27 member states that lost most of their GDP are countries with close historical and political ties to the UK, e.g. Ireland and Germany, and small open economies close to the UK, Belgium, and the Netherlands. In particular, Ireland suffers losses, in terms of relative LiVA, slightly below the UK in the soft Brexit scenario and even higher than the UK in the hard Brexit scenario.

Tables 1 and 2 show, for each country, the sector that will be the most affected under the soft and hard Brexit scenarios. Under a soft Brexit scenario the worst affected sectors, in absolute and relative terms, are the UK (GBR) sector Administrative Service and the Irish sector Paper products, respectively. The German Motor Vehicles sector as well as the Administrative Service industry in France and the Wholesale Trade sector in the Netherlands, also face particularly large absolute LiVA.

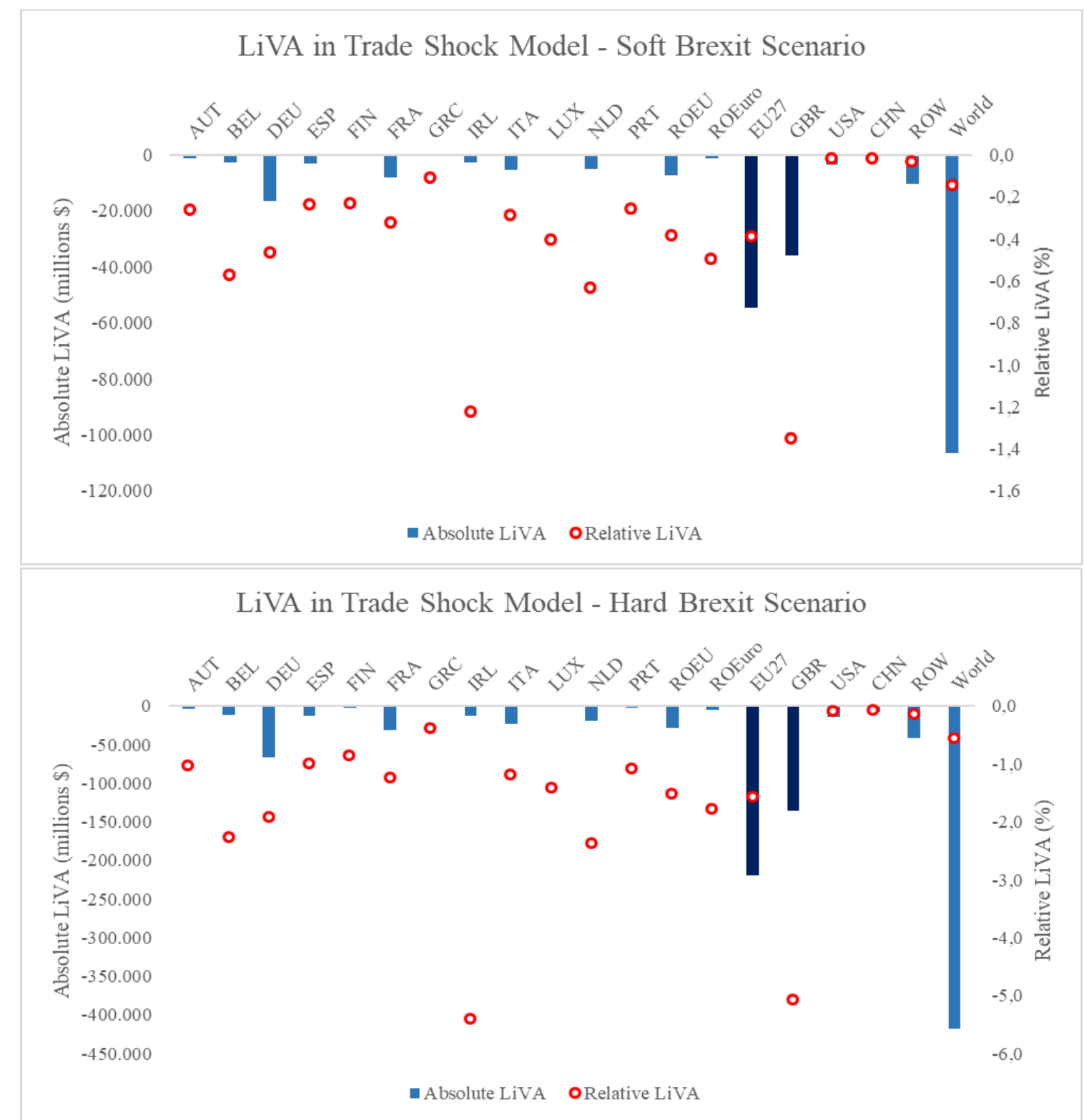

Figures 14 \& 15. Per Country value added losses in the soft and hard Brexit scenarios. Note: blue charts correspond to absolute losses in value added, as given on the left-hand axis. Red dots correspond to percentage losses to value added, as given on the right-hand axis. For country codes see Table A.1 Appendix. 
Trade Shock Model Soft Brexit

\begin{tabular}{|c|c|c|c|c|c|c|c|c|}
\hline & \multicolumn{4}{|c|}{ Most affected sectors in absolute terms } & \multicolumn{4}{|c|}{ Most affected sectors in relative terms } \\
\hline & Sector & $\begin{array}{c}\text { WIOD } \\
\text { Code }\end{array}$ & $\begin{array}{l}\text { Absolute } \\
\text { LiVA }\end{array}$ & $\begin{array}{c}\text { Relative } \\
\text { LiVA }\end{array}$ & Sector & $\begin{array}{c}\text { WIOD } \\
\text { Code }\end{array}$ & $\begin{array}{c}\text { Absolute } \\
\text { LiVA }\end{array}$ & $\begin{array}{c}\text { Relative } \\
\text { LiVA }\end{array}$ \\
\hline AUT & Wholesale Trade & G46 & $-92,56$ & $-0,40 \%$ & Transport Equipment & $\mathrm{C} 30$ & $-21,12$ & $-1,80 \%$ \\
\hline BEL & Legal and Accounting & M69_70 & $-225,24$ & $-0,66 \%$ & Transport Equipment & $\mathrm{C} 30$ & $-44,28$ & $-4,28 \%$ \\
\hline DEU & Motor Vehicles & $\mathrm{C29}$ & $-2492,85$ & $-1,78 \%$ & Transport Equipment & $\mathrm{C} 30$ & $-321,36$ & $-1,80 \%$ \\
\hline ESP & Motor Vehicles & $\mathrm{C} 29$ & $-254,45$ & $-2,21 \%$ & Motor Vehicles & $\mathrm{C} 29$ & $-254,45$ & $-2,21 \%$ \\
\hline FIN & Paper products & C17 & $-48,02$ & $-1,27 \%$ & Petroleum products & C19 & $-7,13$ & $-1,50 \%$ \\
\hline FRA & Administrative Service & $\mathrm{N}$ & $-1383,37$ & $-1,01 \%$ & Textiles & C13-15 & $-139,07$ & $-2,02 \%$ \\
\hline GRC & Water Transport & $\mathrm{H} 50$ & $-52,75$ & $-0,70 \%$ & Basic Metals & $\mathrm{C} 24$ & $-19,01$ & $-0,97 \%$ \\
\hline IRL & Food, Beverage and Tobacco & $\mathrm{C} 10-12$ & $-587,35$ & $-5,12 \%$ & Paper products & $\mathrm{C17}$ & $-10,82$ & $-9,45 \%$ \\
\hline ITA & Textiles & C13-15 & $-423,04$ & $-1,39 \%$ & Transport Equipment & $\mathrm{C} 30$ & $-116,44$ & $-1,54 \%$ \\
\hline LUX & Financial Services & K64 & $-40,32$ & $-0,47 \%$ & Transport Equipment & $\mathrm{C} 30$ & $-0,24$ & $-1,59 \%$ \\
\hline NLD & Wholesale Trade & G46 & $-700,80$ & $-1,06 \%$ & Textiles & C13-15 & $-43,08$ & $-2,92 \%$ \\
\hline PRT & Textiles & $\mathrm{C} 13-15$ & $-64,81$ & $-1,34 \%$ & Transport Equipment & $\mathrm{C} 30$ & $-4,25$ & $-2,36 \%$ \\
\hline ROEU & Wholesale Trade & G46 & $-559,78$ & $-0,48 \%$ & Transport Equipment & $\mathrm{C} 30$ & $-111,42$ & $-1,44 \%$ \\
\hline ROEuro & Real Estate & L68 & $-151,77$ & $-0,74 \%$ & Transport Equipment & $\mathrm{C} 30$ & $-7,39$ & $-1,85 \%$ \\
\hline USA & Administrative Service & $\mathrm{N}$ & $-398,07$ & $-0,06 \%$ & Waste Collection Activities & E37-39 & $-67,65$ & $-0,16 \%$ \\
\hline $\mathrm{CHN}$ & Electronics and Computers & $\mathrm{C} 26$ & $-204,89$ & $-0,08 \%$ & Electronics and Computers & $\mathrm{C} 26$ & $-204,89$ & $-0,08 \%$ \\
\hline ROW & Mining and Quarrying & $\mathrm{B}$ & $-2657,53$ & $-0,12 \%$ & Mining and Quarrying & B & $-2657,53$ & $-0,12 \%$ \\
\hline GBR & Administrative Service & $\mathbf{N}$ & $-3231,54$ & $-2,55 \%$ & Electronics and Computers & $\mathrm{C26}$ & $-1267,43$ & $-6,77 \%$ \\
\hline EU27 & Wholesale Trade & G46 & $-4125,17$ & $-0,55 \%$ & Transport Equipment & C30 & $-1129,90$ & $-1,8 \%$ \\
\hline World & Wholesale Trade & G46 & $-8485,84$ & $-0,18 \%$ & Pharmaceutical & $\mathrm{C} 21$ & $-2744,99$ & $-0,60 \%$ \\
\hline
\end{tabular}

Table 1. Most affected sectors in each country in absolute (millions \$) and relative (\%) LiVA terms. Soft Brexit scenario.

Trade Shock Model Hard Brexit

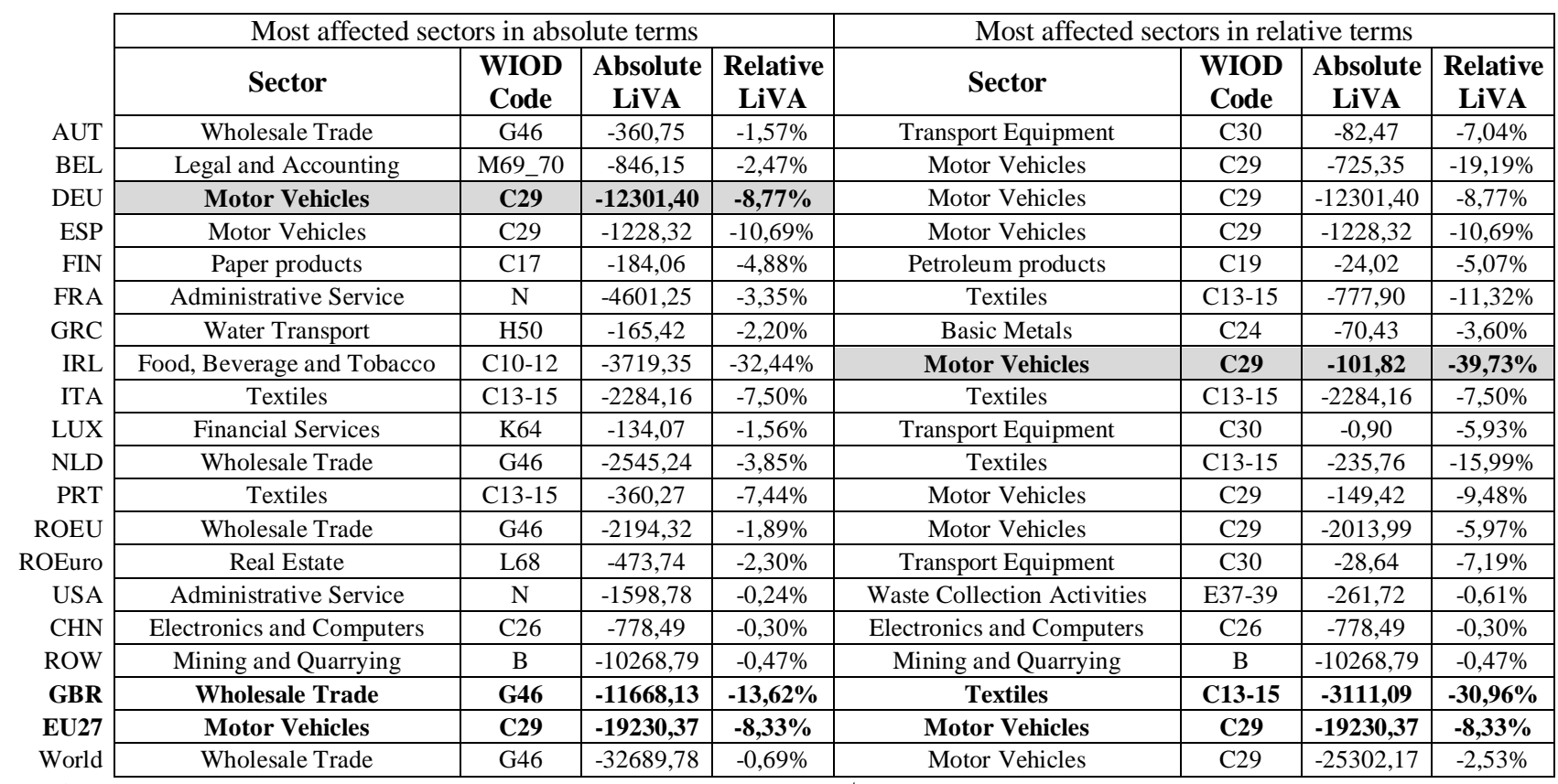

Table 2. Most affected sectors in each country in absolute (millions \$) and relative (\%) LiVA terms. Hard Brexit scenario.

Summing up the losses incurred by each sector in each country we find that the sector most affected in the world is the Wholesale Trade sector. The same result is obtained by limiting the sum of sectoral losses to EU27 member states.

Moving from the soft to the hard Brexit scenario, results are similar, though different in the magnitude of losses and with some relevant distinctions. Indeed, if we introduce the tariffs in our model the ranking of the most affected sectors changes. Table 2 shows that, in terms of absolute LiVA, the German Motor Vehicles sector will be the worst affected industry in the case of a no-deal scenario. Furthermore, the 
same industry placed in Ireland will be also the most influenced in relative LiVA terms. These results are confirmed by the fact that the automotive sector is generally the most sensitive to tariffs in EU27 in both absolute and relative terms. In this scenario, as expected, the UK sectors also suffer large losses, in particular, the Wholesale Trade sector, which is in absolute the most affected in the world, and the textile sector, the most affected in relative terms.

Summarising, our results for the trade shock model suggest that in both scenarios Brexit could be risky and costly not only for the UK but also for EU countries. There will be no Brexit winners, although some trade policies could mitigate the losses. These are further discussed in the following section.

\subsection{Domestic Import Substitution-Trade Diversion Model Results}

In this sub-section, we show the results obtained introducing the hypotheses that in response to Brexit, UK trade will be partly diverted to extra-EU countries and EU imported products will be partly substituted by domestic purchases. Conversely, on the other side of the Channel we assume that EU countries will partly substitute UK imported products by intra-EU purchases.

Figures 16 and 17 summarise the results for the domestic import substitution and trade diversion (DISTD) model showing the absolute and relative LiVA for all 18 countries in the dataset. The first remark we can draw is that in both scenarios the losses are significantly lower for the United Kingdom and for each EU27 member state. In particular, here the UK is no longer the most affected country. Rather, estimated losses in the UK ranging from a LiVA of \$1.4 billion in the soft Brexit scenario to a surprisingly negative LiVA, i.e. a gain of $\$ 10.6$ billion in the hard Brexit scenario. This corresponds to a drop in value added production as a percentage of GDP of 0.05 percent under a soft Brexit and to a rise of 0.4 percent under a hard Brexit scenario. Hence, introducing the hypothesis of DIS-TD the UK would even benefit from a no-deal scenario. Clearly, this conclusion relies on the assumption that UK would be actually able to substitute EU imported products with domestics and to partly divert its trade to extra-EU countries. Thus, the UK should be able to implement a trade policy to achieve a trade agreement with extra-EU countries, and at the same time, it should invest in domestic sectors and implement a strategic industrial plan to make domestic production competitive with EU goods. This may prove too ambitious.

Outside the UK, losses are larger, although the absolute and relative LiVA are heterogeneously distributed among sectors and countries. The most affected EU27 countries in terms of absolute and relative losses are Germany, France, Ireland, Italy, the Netherlands and the region we labelled Rest of Europe, for both the soft and hard Brexit scenarios. In the latter case also Spain and Belgium face a large LiVA. However, compared to the previous trade shock model, results suggest that if EU countries would be able to divert some of their trade substituting part of UK imported products by intra-EU purchases, losses will be more modest.

\section{Discussion}

In this section, we discuss our main findings for both models developed, and relating them back to some of the relevant studies that investigated the potential impact of Brexit.

The trade shock model employed in this paper, delivers estimates about the losses the UK will face that are broadly similar to the results in the literature which has focused on the trade effects of Brexit (Dhingra et al., 2017; Aichele and Felbermayr, 2015; Kierzenkowski et al., 2016; Rojas-Romagosa, 2016; and Booth et al., 2016). Our results suggest that under the soft and hard Brexit scenarios, the UK faces relative losses which are three times larger than EU27 expected losses, and range from 1.35 to 5.07 percent of GDP. However, when we compare our results to the predictions outlined in earlier studies that also consider the impact of Brexit on the EU27, our estimated value added losses for the EU27 are much 
higher. Actually, our findings indicate that the absolute losses in value added production for the EU27 are significantly larger than those of the UK. Besides the fact that EU27 is a much larger economy than the $\mathrm{UK}$, this result is partly due to the EU27 being directly exposed to increasing UK tariff costs, with the UK running an increasingly large trade deficit with the EU27, especially in trade in goods, which are usually dutiable. The inclusion of indirect trade effects in our model represents a potential alternative explanation for the larger absolute losses we found for the EU27. Indeed, EU production network is closely integrated, which implies that tariff changes with the UK do not affect only direct trade flows, but also indirect trade flows via other EU countries. Therefore, the inclusion of indirect trade effects would lead to larger absolute losses for all the EU27 member states and the EU27 as a whole. This highlights the importance of including indirect trade in economic analysis of trade shocks. Nevertheless, the study by Vandenbussche et al. (2017) which also include in their analysis complex supply chain linkages gives similar results for the EU27 as those derived from the econometric model shown in J. Chen et al. (2018).

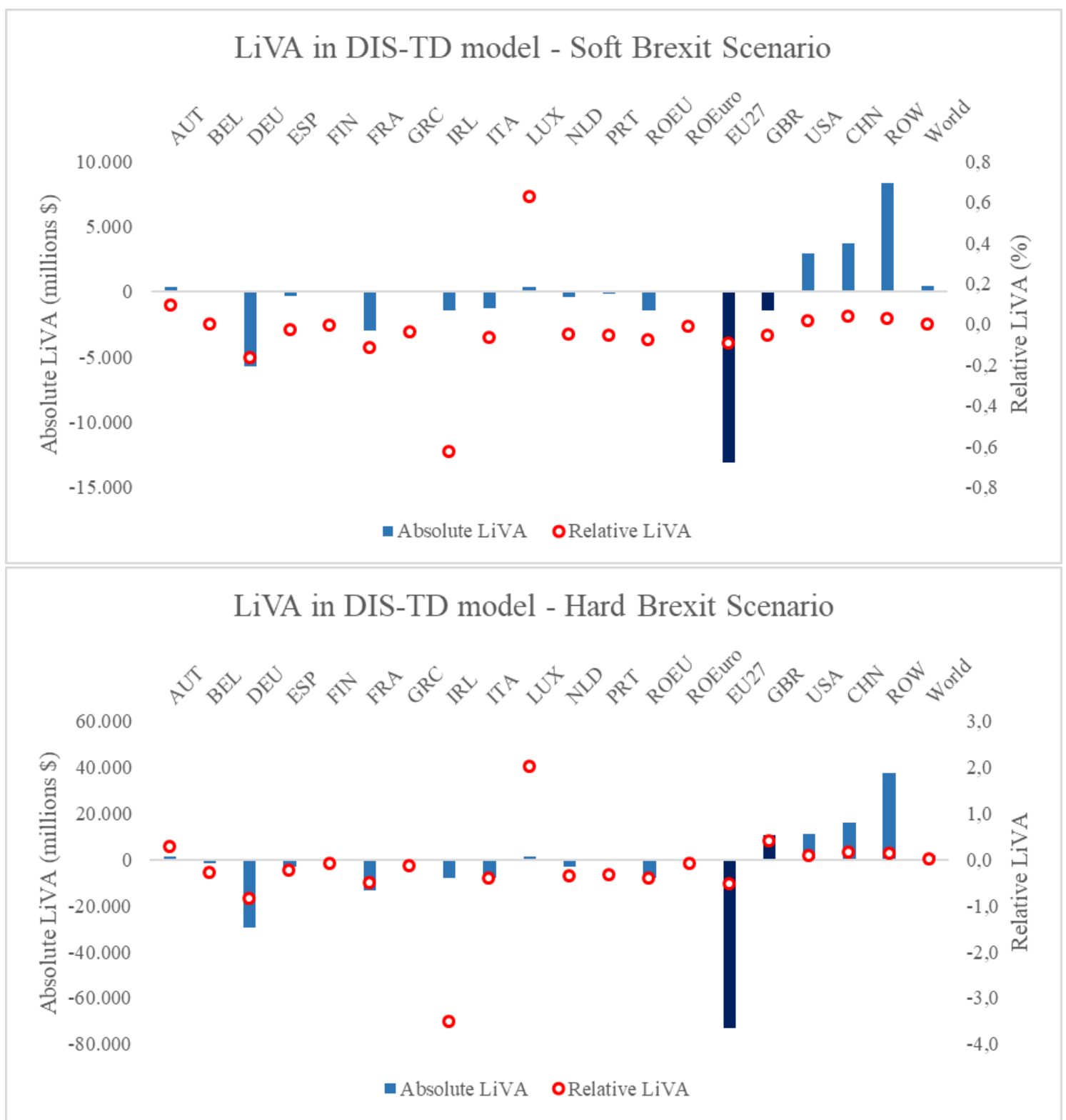

Figures 16 \& 17. Per Country value added losses in the soft and hard Brexit scenarios. Note: blue charts correspond to absolute losses in value added, as given on the left-hand axis. Red dots correspond to percentage losses to value added, as given on the right-hand axis. For country codes see Table A.1 Appendix. 
Our analysis found that, outside the UK, the most affected individual countries were Germany, France, Ireland, Belgium, and the Netherlands. All within the EU, these countries also correspond to some of the UK's top source and destination countries and thus are highly reliant on UK consumers and businesses for trade. These results are supported by the findings showed by Vandenbussche et al. (2017). Supporting the work of W. Chen et al. (2018) who find that some regions in Ireland are just as exposed to Brexit as some UK regions, the results show that Ireland faces similar relative value added losses to the UK in both scenarios. Overall, this suggests that Brexit would be risky and costly also for EU27, hence, the negotiation of a Brexit deal is crucial for countries across the EU27 not just for the UK.

In motivating their methodology W. Chen et al. (2018) list a number of shortcomings in the studies aiming at quantifying the actual changes in the UK and EU countries GDP due to Brexit. One of these, concerns the lack of models that allow contemplating a post-Brexit world in which the UK trade could be largely diverted to extra-EU countries and the UK and EU countries could substitute imported products by domestic purchases. Our DIS-TD model simulates this world, though not immune to all the criticisms made by W. Chen et al. (2018). As shown in the previous section, introducing the hypothesis of domestic import substitution and trade diversion leads to different estimates about the potential impact of Brexit on both macro-regions. In particular, we find the absolute and relative losses in value added production for the UK and for each EU27 member state to be significantly lower compared to the results shown in the Brexit literature and in our trade shock model. A potential explanation for the lower estimates delivered by our DIS-TD model is that we move away from the usual claim underlying standard trade models according to which trade liberalisation always tend to increase welfare. In our second model, trade barriers would not necessarily mean negative economic shocks, because we allow sectors and countries to partly substitute foreign products, which are rendered less competitive due to tariffs. This change to the model leads to results in line with Rodrik (2018b, c) and Skidelsky (2016) remarks, according to which, under circumstances of weak domestic growth and growing trade deficit, trade protectionism and domestic import substitution policies would be preferable to unconditional free trade.

\section{Conclusion}

This paper has two main purposes. First, provide a detailed and holistic discussion of the UK's decision to leave the EU and how it will affect international trade networks and value-added, globally. Second, explore if there are options available to policy-makers so that Brexit does not result in huge economic losses.

The first aim required the construction of a model that would allow us to identify all the channels through which the economic effects of Brexit would propagate within and among sectors and countries. Thus, we employed the World Input-Output Database (WIOD) to develop a multi-sector inter-country model that includes trade in intermediate and final goods and services, in order to track, at the industry level, the direct and indirect effect of Brexit along global value chains. The inclusion of indirect effects makes our predictions different with respect to the results in the main literature, or at least regarding the losses expected for Europe. Indeed, our model simulation suggests that EU27 would face larger absolute losses than what emerges in the literature. Absolute losses for the EU27 are even bigger than those the UK suffers, and range from $\$ 54$ billion under a free trade agreement scenario to $\$ 218$ billion under a nodeal scenario. However, in line with the literature, we find the UK be the most affected country, facing value-added losses of $\$ 36$ billion and $\$ 135$ billion for the soft and hard Brexit scenarios, respectively.

The second purpose of the paper required the study of the main features of UK trade patterns, the detection of geographical composition of UK trade in goods and services, and the analysis of the UK balance of payments, in order to find if there is room to boost domestic growth by implementing industrial and trade policies in the UK. In the third and fourth section, UK trading relationships were analysed, 
taking both a long-term and a static view, concluding that the UK economy has experienced deindustrialisation and 'servification' in the past 15 years. This trend has returned a significant and growing deterioration in the UK trade balance with Europe, especially in manufacturing, that has led to widespread calls for rebalancing the economy (Coutts and Rowthorn, 2013) culminated in the vote for Brexit (Los et al., 2017). Hence, we modify the first model interpreting Brexit as a special case in which a country implements a protectionist trade policy in order to rebalance the external accounts and boost domestic growth. This second model builds on Rodrick (2018a, 2018b, 2018c) remarks, according to which under circumstances of weak domestic growth and growing trade deficit, trade protectionism would be preferable to unconditional free trade. The inclusion of the hypotheses that in response to Brexit, (1) UK trade will be partly diverted to extra-EU countries, (2) EU imported products will be partly substituted by domestic purchases, (3) EU countries will partly substitute UK imported products by intra-EU purchases, returns absolute and relative losses for the UK and EU27 significantly lower. In particular, estimated losses in the UK ranging from $\$ 1.4$ billion in the soft Brexit scenario to a surprisingly gain of $\$ 10.6$ billion in the hard Brexit scenario. Outside the UK, losses are larger, although significantly below to the first model estimates.

The results achieved in the second model should not be used to claim that Brexit would bring benefits to the UK. However, since the UK decision to leave Europe has been taken, the main economic literature produced a large body of material explaining why that decision has been wrong. In contrast, there has been no post-vote material emerging helping understand how to deal with the implications of this decision to curb welfare losses. In this sense, the present paper fills this gap exploring some available policy options to address the economic impact of Brexit. The main conclusion is that a passive attitude towards the Brexit by the UK government could lead to huge losses for the UK as well as for EU27. On the other hand, a trade and industrial plan in the UK could have positive implications globally. Ultimately, both macroregions should wish to conclude a trade agreement that does not result in significant losses for the UK and in turn for EU27 countries.

The study conducted provides some novelty. First, the multi-sector inter-country model developed in the paper complements traditional trade models, offering a comprehensive view of the direct and indirect effects involved in Brexit. More generally, our model allows verifying how the economic impact of tariffs would propagate within an IO production network. Second, we challenge the traditional assumption underlying standard trade models, according to which trade liberalisation always increases welfare. The second model we develop includes domestic import substitution and trade diversion policies, i.e. we allow sectors and countries to partly substitute foreign products turned less competitive due to tariffs. Considering that new trade wars are on the horizon at a global level, for example between the US and China, our models could prove to be a useful tool in future researches. Finally, the models we developed enrich the multi-regional IO literature adopting in an inter-country framework, an extension of the wellknown hypothetical extraction technique, namely the partial hypothetical extraction method introduced by Dietzenbacher and Lahr (2013). Furthermore, for the first time the partial hypothetical expansion, described in Dietzenbacher and Lahr (2013) to consider the import substitution cases, has been applied to an empirical analysis.

Along with these novelties, our study includes some limits. For example, we do not include the potential effects of Brexit due to immigration paths, foreign direct investment and firm relocation decisions (Commendatore et al., 2018). Although, several studies suggest that trade effects account for the main part of the Brexit impact (Vandenbussche et al., 2017). Furthermore, the models developed are static and hence fail in consider all the possible interactions among the variables involved. In this sense, the emerging literature on dynamic non-linear IO models (see the view of Dietzenbacher in Dietzenbacher et al., 2013) with endogenous growth (Gualdi and Mandel, 2018) and financial networks (Bigio and La'O, 2016; Battiston et al., 2007; Delli Gatti et al., 2010), seems fruitful for future investigations. 


\section{References}

Acemoglu, D., Carvalho, V., Ozdaglar, A. and Tahbez-Salehi, A., 2012. The Network Origins of Aggregate Fluctuations, Econometrica 80(5).

Aichele, R., Felbermayr, G., 2015. Costs and benefits of a United Kingdom exit from the European Union. GED Study, Bertelsmann Stiftung.

Aiello, F., Bonanno, G., Via, A., 2015. Again on trade elasticities: evidence from a selected sample of countries, Eurasian Bus Rev (2015) 5:259-287.

Alatriste-Contreras, M., G., Fagiolo, G., 2014. Propagation of Economic Shocks in Input-Output Networks: A Cross-Country Analysis, Physical Review E, Vol. 90, 062812.

Balassa, B., 1979. Accounting for Economic Growth: the Case of Norway, Oxford Economic Papers, Volume 31, Issue 3, 1 November 1979, Pages 415-436

Baldwin, R., 2016. Brexit Beckons: thinking ahead by leading economists. Baldwin, Richard E ed. Publication info: London, CEPR Press.

Battiston, S., Delli Gatti, D., Gallegati, M., Greenwald, B. and Stiglitz, J., 2007. Credit chains and bankruptcy propagation in production networks, Journal of Economic Dynamics and Control, 31, issue 6, pp. 2061-2084.

Becker, S., Fetzer, T., \& Novy, D., 2017. Who voted for Brexit? A comprehensive district-level analysis. Economic Policy, 32(92), 601-650.

Berden, K., Francois, J., Tamminem, S., Thelle, M. and Wymenga, P., 2013. Non-Tariff Measures in EU-US Trade and Investment: An Economic Analysis, IIDE Discussion Papers 20090806, Institute for International and Development Economics.

Bigio, S., La'O, J., 2016. Financial frictions in production networks. National Bureau of Economic Research, Working Paper (22212).

Booth, S., Howarth, C., Persson, M., Ruparel, R., Swidlicki, P., 2015. What if ...? The consequences, challenges and opportunities facing Britain outside the EU, Open Europe Report, No. 3, London.

Bruton, H., J., 1998. A Reconsideration of Import Substitution, Journal of Economic Literature, Vol. 36, No. 2, pp. 903-936.

Busch, B., Matthes, J., 2016. Brexit - the economic impact: A meta-analysis, IW-Reports 10/2016, Institut der deutschen Wirtschaft (IW) / German Economic Institute.

Cambridge Econometrics, 2018. Preparing for Brexit, Report for Greater London Authority, January.

Cappariello, R., Damjanovic, M., Mancini, M., Vergara Caffarelli, F., 2018. EU-UK global value chain trade and the indirect costs of Brexit. Questioni di Economia e Finanza, Occasional Papers, Bank of Italy. Number 468 - November.

Chen, J., Ebeke, E., Lin, L., Qu, H., Schoelermann, H., Siminitz, J., 2018. The Long-Term Impact of Brexit on the European Union. IMF Country Report No. 18/224.

Chen, W., Los, B., McCann, P., Ortega-Argilés, R., Thissen, M., \& van Oort, F., 2018. The continental divide? Economic exposure to Brexit in regions and countries on both sides of The Channel. Papers in Regional Science, 97(1), 25-54.

Colantone, I., Stanig, P., 2018. Global Competition and Brexit. American Political Science Review, 112(2), pp. 201-218. https://doi.org/10.1017/S0003055417000685 
Commendatore, P., Kubin, I., Sushko, I., 2018. The impact of Brexit on trade patterns and industry location: a NEG analysis. Department of Economics Working Papers Series. Vienna: WU Vienna University of Economics and Business.

Costinot, A. and Rodriguez-Clare, A., 2014. Trade theory with numbers: Quantifying the consequences of globalization, Technical report, National Bureau of Economic Research.

Coutts, K., Gudgin, G., Buchanan, J., 2018. How the Economics Profession Got It Wrong on Brexit, Working Papers wp493, Centre for Business Research, University of Cambridge.

Coutts, K., Rowthorn, R., 2013. The UK balance of payments: structure and prospects, Oxford Review of Economic Policy, Volume 29, Number 2, 2013, pp. 307-325.

Crafts, N., 2016. The Growth Effects of EU Membership for the UK: A Review of the Evidence, Social market Foundation Global Perspectives Series Paper 7.

Cripps, F., Godley, W.A.H., 1976. A Formal Analysis of the Cambridge Economic Policy Group Model, Economica New Series, Vol. 43, No. 172, pp. 335-348

Delli Gatti, D., Gallegati, M., Greenwald, B., C., Russo, A., Stiglitz, J., E., 2010. The financial accelerator in an evolving credit network. Journal of Economic Dynamics \& Control 34 (2010) 16271650.

Dietzenbacher, E., \& Lahr, M.L., 2013. Expanding extractions. Economic Systems Research, 25, 341360.

Dietzenbacher, E., Lenzen, M., Los, B., Guan, D., Lahr, M.L., Sancho, F., Suh, S., Yang, C., 2013. Input-output analysis: the next 25 years, Economic Systems Research, 25:4, 369-389, DOI: $10.1080 / 09535314.2013 .846902$

Dietzenbacher, E., Los, B., Stehrer, R., Timmer, M. P., \& de Vries, G., 2013. The construction of world input-output tables in the WIOD project. Economic Systems Research, 25, 71-98.

Dietzenbacher, E., van der Linden, J.A., Steenge, A.E., 1993. The Regional Extraction Method: EC Input-Output Comparisons. Economic Systems Research, 5, 185-206.

Dhingra, S., Huang, H., Ottaviano, G., Pessoa, J., Sampson, T. and Van Reenen, J., 2017. The costs and benefits of leaving the EU: Trade effects, CEP Discussion paper 1478.

Gagnon, J. E., 2013. Currency wars. The Milken Institute Review, 15(1), 47-55.

Godley, W.A.H., and May, R., 1977. The Macroeconomic Implications of Devaluation and Import Restrictions. Cambridge Economic Policy Review, 1977, 3, 32-42.

Greenaway, D., 1983. International Trade Policy: From Tariffs to the New Protectionism. The MACMILLAN Press LTD, London, England-United Kingdom.

Greenaway, D., Milner, C., 2003. Effective Protection, Policy Appraisal and Trade Policy Reform. The World Economy, 26(4): 441-456. https://doi.org/10.1111/1467-9701.00531

Gualdi, S., Mandel, A., 2018. Endogenous Growth in Production Networks. J Evol Econ (2018). https://doi.org/10.1007/s00191-018-0552-X

Gudgin G, Coutts K, Gibson N, and Buchanan J., 2017a. The Role of Gravity Models in estimating the Economic Impact of Brexit. Centre forBusiness Research, University of Cambridge Working Paper No. 490.

Gudgin G, Coutts K, Gibson N, and Buchanan J., 2017b. Defying Gravity. A Critique of estimates of the Economic Impact of Brexit. Policy Exchange. London. 
Head, K., and T. Mayer, 2014. Gravity Equations: Workhorse,Toolkit, and Cookbook, chapter 3 in Gopinath, G, E. Helpman and K. Rogoff (eds), vol. 4 of the Handbook of International Economics, Elsevier: 131-195.

Imbs, J., Mejean, I., 2017. Trade elasticities, Review of International Economics 25(2), 383- 402.

Johnson, R. C., 2014. Five facts about value-added exports and implications for macroeconomics and trade research, The Journal of Economic Perspectives 28(2), 119-142.

Joyce, M., Lasaosa, A., Stevens, I., \& Tong, M., 2011. The financial market impact of quantitative easing in the United Kingdom. International Journal of Central Banking, 7, 113-161.

Kaldor N., 1966. Causes of the Slow Rate of Growth of the United Kingdom, Cambridge, Cambridge University Press.

Kaldor N., 1975. Economic Growth and the Verdoorn Law, in «Economic Journal», 85, pp. 891-896.

Kamitake Y., 1990. The Process of De industrialization in Modern Economic History: Lessons from British Historical Experience, in «Hitotsubashi Journal of Economics», 31, pp. 49-59.

Kierzenkowski, R., Pain, N., Rusticelli, E. and Zwart, S., 2016. The Economic Consequences of Brexit: A Taxing Decision, OECD Economic Policy Paper 16.

Koopman, R., Wang, Z., \& Wei, S.-J., 2014. Tracing value-added and double counting in gross exports. American Economic Review, 104(2), 459-494.

Los, B., McCann, P., Springford, J., \& Thissen, M., 2017. The mismatch between local voting and the local economic consequences of Brexit. Regional Studies, 51(5), 786-799.

Los, B., Timmer, M. P., \& de Vries, G. J., 2016. Tracing value-added and double counting in gross exports: Comment. American Economic Review, 106(7), 1958-1966.

Miller, R.E., 1966. Interregional Feedbacks in Input-Output Models: Some Preliminary Results. Papers, Regional Science Association, 17, 105-125.

Miller, R. E., Blair, P. D., 2009. Input-output analysis; foundations and extensions (2nd ed.). Cambridge, UK: Cambridge University Press.

Miller, R.E., Lahr, M.L., 2001. A Taxonomy of Extractions. In: M.L. Lahr and R.E. Miller (eds.) Regional Science Perspectives in Economic Analysis. Amsterdam: Elsevier Science, 407-44.

Mulabdic, A., Osnago, A., and Ruta, M., 2017. Deep Integration and UK- EU Trade Relations, Policy Research Working Paper Series 7947, The World Bank.

Noguera, G., 2012. Trade costs and gravity for gross and value added trade, Job Market Paper, Columbia University.

Norman, N.R., 1996. A General Post Keynesian Theory of Protection, Journal of Post Keynesian Economics, 18:4, 509-531.

Ottaviano, G., Pessoa, J., Sampson, T. and Van Reenen, J., 2014. The Costs and Benefits of Leaving the EU, Centre for Economic Performance Policy Analysis.

Piermartini, R., Teh, R., 2005. Demystifying Modelling Methods for Trade Policy, WTO Discussion Paper, No. 10.

Plummer, M. G., Cheong, D., Hamanaka, S., 2010. Methodology for Impact Assessment of Free Trade Agreements, Asian Development Bank, Mandaluyong City, pp. 20-25. 
Rojas-Romagosa, H., 2016. Trade effects of Brexit for the Netherlands. CPB Background Document, June 2016.

Rodrik D., 2018a. Populism and the economics of globalization. Journal of International Business Policy. Volume 1, Issue 1-2, pp 12-33.

Rodrik, D., 2018b. How to Avoid a Trade War - Project Syndicate - July 10, 2018. https://www.projectsyndicate.org/commentary/china-europe-reaction-trump-trade-tariffs-by-dani-rodrik-2018-07

Rodrik, D., 2018c. Can Trade Agreements Be a Friend to Labor? - Project Syndicate - September 14, 2018. https://www.project-syndicate.org/commentary/trade-agreement-labor-provisions-small-practicaleffect-by-dani-rodrik-2018-09

Rowthorn, R., Coutts, K., 2004. De-industrialisation and the balance of payments in advanced economies, Cambridge Journal of Economics, Volume 28, Issue 5, Pages 767-790.

Rowthorn, R. E. and J. R. Wells, 1987. De-industrialisation and Foreign Trade, Cambridge, Cambridge University Press.

Singh, A., 1989. Third World competition and de-industrialisation in advanced countries, Cambridge Journal of Economics 13(1), 103-120.

Skidelsky, R., 2016. The Case for UK Import Substitution - Project Syndicate - October 21, 2016. https://www.project-syndicate.org/commentary/case-for-uk-import-substitution-by-robert-skidelsky2016-10

Springford, J., McCann, P., Los, B., \& Thissen, M., 2016. Brexiting yourself in the foot: Why Britain's Eurosceptic regions have most to lose from EU withdrawal. London: Centre for European Reform (CER).

Stone, R., 1970. Foreign Trade and Full Employment: An Input-Output Analysis, in Richard Stone (ed.), Mathematical models of the economy and other essays, Chapman \& Hall, London.

Thirlwall A.P., 1979. The Balance of Payments Constraint as an Explanation of International Growth Rate Differences, Banca Nazionale del Lavoro Quarterly Review, 32 (1), pp. 45-53.

Thirlwall A.P., 2001. The Euro and Regional Divergence in Europe, chapter 2 in Martin Holmes (eds), The Eurosceptical Reader 2, PALGRAVE, New York.

Timmer, M.P., Dietzenbacher, E., Los, B., Stehrer, R. and de Vries, G. J., 2015. An illustrated user guide to the world input-output database: the case of global automotive production, Review of International Economics 23(3), 575-605.

Treasury, H. M., 2016. HM Treasury analysis: the long-term economic impact of EU membership and the alternatives. Parliament by the Chancellor of the Exchequer by command of Her Majesty, April.

United Nations Conference on Trade and Development (UNCTAD), 2013. Global Value Chains and Development: Investment and Value Added Trade in the Global Economy, Advance Unedited Version.

Vandenbussche, H., Connell, W., \& Simons, W., 2017. Global value-chains, trade shocks and jobs: An application to Brexit. In CEPR Discussion Paper DP123030. London, UK: Centre for Economic Policy Research. 


\section{Appendix}

\begin{tabular}{|c|c|c|}
\hline $\begin{array}{c}\text { Country/Region } \\
\text { Number }\end{array}$ & $\begin{array}{l}\text { WIOD Country/Region } \\
\text { Code }\end{array}$ & $\begin{array}{c}\text { Country Name/ Countries included in } \\
\text { Region }\end{array}$ \\
\hline 1 & AUT & $\begin{array}{l}\text { Austria } \\
\end{array}$ \\
\hline 2 & BEL & Belgium \\
\hline 3 & DEU & Germany \\
\hline 4 & ESP & Spain \\
\hline 5 & FIN & Finland \\
\hline 6 & FRA & France \\
\hline 7 & GRC & Greece \\
\hline 8 & IRL & Ireland \\
\hline 9 & ITA & Italy \\
\hline 10 & LUX & Luxembourg \\
\hline 11 & NLD & Netherlands \\
\hline 12 & PRT & Portugal \\
\hline 13 & GBR & United Kingdom \\
\hline 14 & ROEU & Rest of EU \\
\hline & & Denmark \\
\hline & & Bulgaria \\
\hline & & Croatia \\
\hline & & Hungary \\
\hline & & Romania \\
\hline & & Sweden \\
\hline & & $\begin{array}{l}\text { Czech Republic } \\
\text { Poland }\end{array}$ \\
\hline 15 & ROEuro & Rest of Eurozone \\
\hline & & Latvia \\
\hline & & Lithuania \\
\hline & & Slovenia \\
\hline & & Estonia \\
\hline & & Malta \\
\hline & & Cyprus \\
\hline & & Slovakia \\
\hline 16 & USA & United States of America \\
\hline 17 & $\mathrm{CHN}$ & China \\
\hline 18 & ROW & Rest of World \\
\hline & & ROW plus the following countries: \\
\hline & & Brazil \\
\hline & & Canada \\
\hline & & India \\
\hline & & Indonesia \\
\hline & & Japan \\
\hline & & South Korea \\
\hline & & Mexico \\
\hline & & Norway \\
\hline & & Russia \\
\hline & & Switzerland \\
\hline & & $\begin{array}{l}\text { Turkey } \\
\text { Taiwan }\end{array}$ \\
\hline
\end{tabular}

Table A.1. Summary of 18 countries in database. 
Trade Shock

\begin{tabular}{|c|c|c|c|c|c|c|c|c|}
\hline & Soft & exit & Hard & exit & Soft & exit & Har & cexit \\
\hline & $\begin{array}{c}\text { Absolute } \\
\text { LiVA }\end{array}$ & $\begin{array}{c}\text { Relative } \\
\text { LiVA }\end{array}$ & $\begin{array}{c}\text { Absolute } \\
\text { LiVA }\end{array}$ & $\begin{array}{c}\text { Relative } \\
\text { LiVA }\end{array}$ & $\begin{array}{c}\text { Absolute } \\
\text { LiVA }\end{array}$ & $\begin{array}{c}\text { Relative } \\
\text { LiVA }\end{array}$ & $\begin{array}{c}\text { Absolute } \\
\text { LiVA }\end{array}$ & $\begin{array}{c}\text { Relative } \\
\text { LiVA }\end{array}$ \\
\hline AUT & $-1021,6$ & $-0,26 \%$ & $-4045,8$ & $-1,04 \%$ & 370,6 & $0,095 \%$ & 1036,6 & $0,27 \%$ \\
\hline BEL & $-2724,9$ & $-0,57 \%$ & $-10797,0$ & $-2,27 \%$ & $-2,7$ & $-0,001 \%$ & $-1433,0$ & $-0,30 \%$ \\
\hline DEU & $-16306,2$ & $-0,47 \%$ & $-66883,7$ & $-1,92 \%$ & $-5754,9$ & $-0,165 \%$ & $-29485,2$ & $-0,85 \%$ \\
\hline ESP & $-2986,3$ & $-0,24 \%$ & $-12600,6$ & $-1,00 \%$ & $-365,1$ & $-0,029 \%$ & $-3082,8$ & $-0,25 \%$ \\
\hline FIN & $-545,1$ & $-0,23 \%$ & $-2021,5$ & $-0,86 \%$ & $-21,1$ & $-0,009 \%$ & $-198,5$ & $-0,09 \%$ \\
\hline FRA & $-8185,9$ & $-0,32 \%$ & $-31538,5$ & $-1,24 \%$ & $-2949,6$ & $-0,116 \%$ & $-13203,5$ & $-0,52 \%$ \\
\hline GRC & $-228,6$ & $-0,11 \%$ & $-804,4$ & $-0,39 \%$ & $-82,8$ & $-0,040 \%$ & $-291,3$ & $-0,14 \%$ \\
\hline IRL & $-2788,7$ & $-1,22 \%$ & $-12292,9$ & $-5,40 \%$ & $-1431,9$ & $-0,629 \%$ & $-8002,0$ & $-3,52 \%$ \\
\hline ITA & $-5556,3$ & $-0,29 \%$ & $-22999,4$ & $-1,20 \%$ & $-1304,9$ & $-0,068 \%$ & $-7957,2$ & $-0,41 \%$ \\
\hline LUX & $-236,3$ & $-0,41 \%$ & $-828,4$ & $-1,42 \%$ & 366,0 & $0,628 \%$ & 1167,0 & $2,00 \%$ \\
\hline NLD & $-5030,7$ & $-0,63 \%$ & $-18855,6$ & $-2,38 \%$ & $-410,6$ & $-0,052 \%$ & $-2980,1$ & $-0,38 \%$ \\
\hline PRT & $-515,7$ & $-0,26 \%$ & $-2171,4$ & $-1,08 \%$ & $-109,0$ & $-0,054 \%$ & $-686,7$ & $-0,34 \%$ \\
\hline ROEU & $-7208,2$ & $-0,39 \%$ & $-28486,5$ & $-1,53 \%$ & $-1418,5$ & $-0,076 \%$ & $-7809,0$ & $-0,42 \%$ \\
\hline ROEuro & $-1283,0$ & $-0,49 \%$ & $-4629,0$ & $-1,79 \%$ & $-31,0$ & $-0,012 \%$ & $-233,4$ & $-0,09 \%$ \\
\hline USA & $-3464,0$ & $-0,02 \%$ & $-14236,3$ & $-0,08 \%$ & 2965,6 & $0,017 \%$ & 11041,2 & $0,06 \%$ \\
\hline $\mathrm{CHN}$ & $-1939,9$ & $-0,02 \%$ & $-7830,7$ & $-0,08 \%$ & 3676,0 & $0,036 \%$ & 16123,2 & $0,16 \%$ \\
\hline ROW & $-10427,9$ & $-0,04 \%$ & $-42003,2$ & $-0,14 \%$ & 8385,5 & $0,028 \%$ & 37369,6 & $0,13 \%$ \\
\hline GBR & $-36043,7$ & $-1,35 \%$ & $-135127,0$ & $-5,07 \%$ & $-1438,4$ & $-0,054 \%$ & 10576,6 & $0,40 \%$ \\
\hline EU27 & $-54617,4$ & $-0,39 \%$ & $-218955,0$ & $-1,57 \%$ & $-13145,4$ & $-0,094 \%$ & $-73158,9$ & $-0,53 \%$ \\
\hline World & $-106493,0$ & $-0,14 \%$ & $-418152,0$ & $-0,57 \%$ & 443,3 & $0,001 \%$ & 1951,7 & $0,00 \%$ \\
\hline
\end{tabular}

Table A.2. Absolute and relative LiVA in trade shock and DIS-TD models, soft and hard Brexit scenarios. 